\title{
Application of PAT-Based Feedback Control Approaches in Pharmaceutical Crystallization
}

\author{
Ye Gao ${ }^{1}$, Teng Zhang ${ }^{1}$, Yiming Ma ${ }^{1}$, Fumin Xue ${ }^{2, *}$, Zhenguo Gao ${ }^{1, * \mathbb{D}}$, Baohong Hou ${ }^{1}$ and Junbo Gong $^{1}$ \\ 1 The Co-Innovation Center of Chemistry and Chemical Engineering of Tianjin, State Key Laboratory of \\ Chemical Engineering, School of Chemical Engineering and Technology, Tianjin University, \\ Tianjin 300072, China; gaoye@tju.edu.cn (Y.G.); zhangteng_@tju.edu.cn (T.Z.); \\ marning_yimingma@tju.edu.cn (Y.M.); houbaohong@tju.edu.cn (B.H.); junbo_gong@tju.edu.cn (J.G.) \\ 2 Key Laboratory for Applied Technology of Sophisticated Analytical Instrument of Shandong Province, \\ School of Pharmaceutical Sciences, Shandong Analysis and Testing Center, Qilu University of \\ Technology (Shandong Academy of Sciences), Jinan 250014, China \\ * Correspondence: xuefumin@qlu.edu.cn (F.X.); zhenguogao@tju.edu.cn (Z.G.)
}

check for updates

Citation: Gao, Y.; Zhang, T.; Ma, Y.; Xue, F.; Gao, Z.; Hou, B.; Gong, J. Application of PAT-Based Feedback Control Approaches in Pharmaceutical Crystallization. Crystals 2021, 11, 221. https://doi.org/10.3390/cryst11030221

Academic Editor: Venu Vangala

Received: 1 February 2021

Accepted: 18 February 2021

Published: 24 February 2021

Publisher's Note: MDPI stays neutral with regard to jurisdictional claims in published maps and institutional affiliations.

Copyright: (c) 2021 by the authors. Licensee MDPI, Basel, Switzerland. This article is an open access article distributed under the terms and conditions of the Creative Commons Attribution (CC BY) license (https:// creativecommons.org/licenses/by/ $4.0 /)$

\begin{abstract}
Crystallization is one of the important unit operations for the separation and purification of solid products in the chemical, pharmaceutical, and pesticide industries, especially for realizing high-end, high-value solid products. The precise control of the solution crystallization process determines the polymorph, crystal shape, size, and size distribution of the crystal product, which is of great significance to improve product quality and production efficiency. In order to develop the crystallization process in a scientific method that is based on process parameters and data, process analysis technology (PAT) has become an important enabling platform. In this paper, we review the development of PAT in the field of crystallization in recent years. Based on the current research status of drug crystallization process control, the monitoring methods and control strategies of feedback control in the crystallization process were systematically summarized. The focus is on the application of model-free feedback control strategies based on the solution and solid information collected by various online monitoring equipment in product engineering, including improving particle size distribution, achieving polymorphic control, and improving purity. In this paper, the challenges of feedback control strategy in the crystallization process are also discussed, and the development trend of the feedback control strategy has been prospected.
\end{abstract}

Keywords: crystallization; feedback control; process analytical technology; polymorphism; crystal size distribution

\section{Introduction}

Crystallization is an important unit operation in major sectors of the chemical process and allied industries. It separated solid substances from solution, vapor, or molten phases [1]. As a key step of solid-liquid separation, the crystallization process could determine the crystal properties such as purity, morphology, polymorph, size, and size distribution, which have a significant impact on the performance of the solid products. For example, the crystal properties could determine drug performances like dissolution behavior, bioavailability, and the efficiency of post-processing technology e.g., filtration, drying [2]. Therefore, the precise control of the crystallization process is of great significance to the improvement of the total efficiency of the production process and the quality of final products.

The actual purpose of crystallization control is to govern the crystal nucleation and growth, which are still not fully understood especially on the subject of solution crystallization. Nucleation and its mechanism are largely studied to get a further understanding of this key stage, mainly focusing on the qualitative and quantitative interactions between the solute, solvent, and external additives, and how the solute molecules self-assemble into 
different crystal forms, and what the exact mechanism and kinetics of nucleation is [3-9]. For growing crystals into the desired size and shape in the manufacturing process, a large portion of the literature is also reported to investigate the crystal growth process and its possible mechanisms [10-15]. Based on modeling and experimental techniques, many works are presently being performed on growth and shape control [10,12,15-18].

The comprehensive effects of critical process parameters (CPPs) make the process fairly complex to understand and volatile to control. Commonly CPPs mainly refer to solvent, supersaturation, impurities, additives, different mixing condition, and scale in the crystallization system. The CPPs can alter the nucleation route and growth kinetics in crystallization, influencing the operation effectiveness, product quality, and even failing to obtain the targeted polymorphic or pseudo-polymorphic (co-crystals, solvates, and hydrates) forms [4-7]. Studies on the crystallization process control, including the mentioned CPPs and process operation mode can benefit a simpler, cheaper, and more robust particle process system. The industrial application and academic study on the control of solution crystallization processes have witnessed significant advances in the past 20 years that have been driven mainly by industrial requirements and enabled by the development of process analytical technology (PAT) [19]. PAT is an interdisciplinary concept that comprises a set of control principles and process monitoring equipment to enhance the understanding and control of the manufacturing process. The application of PAT is the key driving force to realize the concept of quality-by-design $(\mathrm{QbD})$ and quality-by-control $(\mathrm{QbC})$ and advanced crystallization control approaches $[2,13,15,19]$.

Many PAT tools have been lately developed and applied for crystallization process monitoring and control through several crystallization control strategies, namely, attenuated total reflectance Fourier transformed infrared spectroscopy (ATR-FTIR) and ultravioletvisible spectroscopy (UV/Vis), particle vision and measurement (PVM), focused beam reflectance measurement (FBRM), in situ/online image analysis, and online Raman spectroscopy. PAT tools improve data quality, monitor flexibility, and ensure the reliability of the process. The in-situ techniques can give signals on the crystalline structure, solute concentration, polymorphic or pseudo-polymorphic form, number, size, and shape of the crystals in the crystallization system, which have been applied for scientific research as well as industrial manufacturing objective. ATR-FTIR can monitor the concentration changes in solution in a real-time mode. In order to correlate the spectral intensity with the solution concentration, the background is accurately processed, and the full spectrum quantitative analysis technology of chemometrics is used to significantly improve the accuracy of the measurement method. The method requires the establishment of a concentration calibration model [8], which is greatly affected by the solvent background and external test conditions. ATR-UV/Vis is a molecular spectrum that generates absorption from valence electron transitions. It uses the qualitative and quantitative relationship between the composition, structure of the substance, and the ultraviolet-visible light absorption spectrum to analyze nucleation, polymorphic transformation, and in situ monitoring of supersaturation changes $[9,10]$. FBRM can track the number of particles and chord length distribution in real-time, providing a quantitative calculation method for crystallization process modeling. The latest generation of FBRM overcomes the problem of probe contamination [11]. As a mature technology, Raman spectroscopy has been used to identify differences in polymorphisms, and it can perform qualitative and quantitative studies on solvent-mediated transformation, solution concentration, and the ratio of different crystal forms in solid mixtures [12]. PVM is a kind of inline micro camera that can visually track nucleation, crystal growth, polymorphic transformation, coalescence, and fragmentation during the crystallization process in real-time [12].

Based on the above-mentioned analysis techniques, in-situ monitoring of the structure and properties of liquid and solid phases in the crystallization process can be realized. The measured information of the solid and liquid phases in the solution can (i) develop a better understanding of the crystallization mechanism and the influence of operating conditions on product performance; (ii) design experiments to measure crystallization 
kinetics; (iii) design controllers to improve product quality and reduce operating costs; (iv) operate the process within the required performance indicators using suitable feedback control strategy [2]. Table 1 summarizes the working principles and applications of these commonly used PAT tools.

Table 1. Summary of the process analytical technology (PAT) tools in the solution crystallization process.

\begin{tabular}{|c|c|c|}
\hline PAT Tools & Working Principle & Application \\
\hline FBRM & $\begin{array}{l}\text { Receive the reflection signal generated by the laser } \\
\text { beam through the particles, and calculate the time } \\
\text { the laser beam passes through the particles to } \\
\text { obtain the chord length distribution }\end{array}$ & $\begin{array}{l}\text { Real-time monitoring of particle size and } \\
\text { particle number changes as well as nucleation } \\
\text { and growth processes [13-15] }\end{array}$ \\
\hline PVM & $\begin{array}{l}\text { The video microscope on the probe can intuitively } \\
\text { display the particle status, continuously capture } \\
\text { high-resolution images under various process } \\
\text { conditions, without the need for sampling or } \\
\text { offline analysis }\end{array}$ & $\begin{array}{l}\text { Monitor nucleation, growth, coalescence, } \\
\text { fragmentation, shape evolution, and } \\
\text { polymorphic behavior of the crystallization } \\
\text { process, endoscope probes can detect } \\
\text { color-related changes [16-18] }\end{array}$ \\
\hline ATR-FTIR & $\begin{array}{l}\text { The crystal sample absorbs infrared light at the } \\
\text { incident frequency, the reflected light intensity is } \\
\text { reduced, and a spectrum similar to the } \\
\text { transmission absorption is generated, thereby } \\
\text { obtaining structural information of the chemical } \\
\text { composition of the sample surface }\end{array}$ & $\begin{array}{l}\text { Infrared measurement of solute concentration } \\
\text { during crystallization [8] }\end{array}$ \\
\hline ATR-UV/Vis & $\begin{array}{l}\text { The ultraviolet-visible absorption spectrum is an } \\
\text { electronic spectrum, which is produced by the } \\
\text { transition of valence electrons. The composition, } \\
\text { content, and structure of a substance can be } \\
\text { analyzed, determined, and infer determined by } \\
\text { using ultraviolet-visible absorption spectrum and } \\
\text { the degree of absorption of ultraviolet-visible light } \\
\text { by substance molecules or ions }\end{array}$ & $\begin{array}{l}\text { In situ monitoring of nucleation [9], crystal } \\
\text { form transformation and supersaturation } \\
\text { changes [10] }\end{array}$ \\
\hline Raman & $\begin{array}{l}\text { Raman spectroscopy is a kind of scattering } \\
\text { spectrum, which is analyzed with different } \\
\text { incident light frequencies to obtain information on } \\
\text { molecular vibration and rotation. Raman } \\
\text { frequency offset is represented by the abscissa, and } \\
\text { Raman intensity is represented by the ordinate, } \\
\text { which is complementary to the infrared spectrum } \\
\text { and available for analyzing information related to } \\
\text { intermolecular bond energy }\end{array}$ & $\begin{array}{l}\text { Identify differences in polymorphic forms and } \\
\text { enable qualitative and quantitative studies on } \\
\text { solvent-mediated transformation, solution } \\
\text { concentration, and the ratio of different } \\
\text { crystalline forms in solid mixtures [20] }\end{array}$ \\
\hline
\end{tabular}

More and more advanced crystallization control strategies and intelligent control systems based on PAT tools are playing an increasingly important role in both lab research and industrial scale [2,21]. This paper reviews the development and application of PAT technology, the feedback control method based on PAT, and its application in the crystallization process.

\section{Solution Crystallization Process Control Approaches}

In most industrial solution crystallization systems, traditional control approaches are designed to follow simple operating curves, for example, linear cooling rate, anti-solvent feed rate, or evaporation rate, but these control strategies often fail to meet multi-target product characteristics optimization control targets [22]. The development of PAT sensors and the improvement of their measurement accuracy have gradually been applied to the field of crystallization, which has achieved the accurate measurement of data such as the concentration of liquid phase and the particle size, morphology, and crystal form of the solid phase, prompting researchers to develop more complete crystals process control 
strategy. The recent advances in modern sensor technology and the crystallization process model have enabled more advanced control strategies to be used more frequently.

The model-free control method is to directly use the measurement value based on PAT to realize crystallization process control. Broadly speaking, model-free control approaches include open-loop control and closed-loop/feedback control approaches. The traditional open-loop control approaches, for instance of the linear control with the constant cooling rate (or antisolvent addition rate), are model-free but simple to understand and implement. In this review, the development and application of feedback control strategies used for various crystallization systems are mainly discussed, which can represent the major advances of model-free crystallization control approaches along with PAT-based measurements. Crystallization process systems are often designed using adaptable feedback control algorithms to reduce the impact of disturbance and promote operational efficiency. The feedback control strategy (e.g., proportional-integral-derivative (PID), cascade) is generally one of the most important elements of an active process control system according to $\mathrm{QbC}$ framework [23]. The model-free feedback control strategy is a feedback control strategy based on the difference between the setpoint and the real-time measured value of factors such as concentration, particle number, and temperature. This method can control the crystallization process in the phase diagram or directly control the properties of the solid phase, which is a relatively intuitive control scheme [24].

The problems of process stability and product consistency exist in the solution process, which will seriously affect the crystal properties. Therefore, stability, i.e., robustness control, should be emphasized in the process of solution crystallization to reduce the influence of abnormal fluctuation of the crystal system, process dynamic parameters, and physical operation parameters. Artificial neural networks (ANN) are also used in the field of crystallization processes [25-29]. The ANN-based PVM and FBRM sensors were developed by Szilagyi et al. [30] and can transform the two-dimensional crystal size distribution to chord length distribution and aspect ratio distribution on arbitrary two-dimensional grids. The software soft sensor based on ANN is used to simulate the most likely average value of the bivariate crystal size distribution (2D CSD), and guide the experiment to control the crystal size and shape [31]. As shown in Figure 1, a radial basis function (RBF) neural network is used to train process operating conditions to optimize crystal product target characteristics [32]. The crystallization process is trained by real-time process data collection, process data mining, and process data storage. The control strategy based on RBF neural network can control and adjust the variation of parameters, such as initial supersaturation, agitation rate, impurity content, seed quality, etc., through limited process data, to reduce the influence of various parameters on the specific crystal properties target [33]. The learning and control of process online data do not depend on the specific process model. It is an online data-driven control strategy, which can effectively avoid the impact of process parameter changes on the final crystal products and process operation objectives. The robust control model based on online data learning can ensure the stability of the optimal control path to achieve the process control objectives.

In the majority of industrial crystallization systems, classical feedback loop control strategies are designed to follow simple heuristic operating policies. A series of feedback control methods have been established relying on online process analysis tools. Based on the accurate in-situ concentration measurement of ATR-FTIR or ATR-UV/Vis spectra, the supersaturation control (SSC)/concentration feedback control (CFC) method was established [34]. The direct nucleation control (DNC) was established by FBRM real-time measurement of the number of particles in the solution [9,35]. Polymorph concentration control (PCC) is based on the online Raman real-time measurement of polymorph in solution [36]. The new image analysis based direct nucleation control (IA-DNC) is established by PVM to monitor particles in solution [37]. The combination of SSC-DNC [38] and the mass-count (MC) framework approach was also established by ATR-FTIR and FBRM in the reported studies [39]. The active polymorphic feedback control (APFC) strategy is based on the use of a combination of Raman and ATR-UV/Vis spectroscopy [40]. 


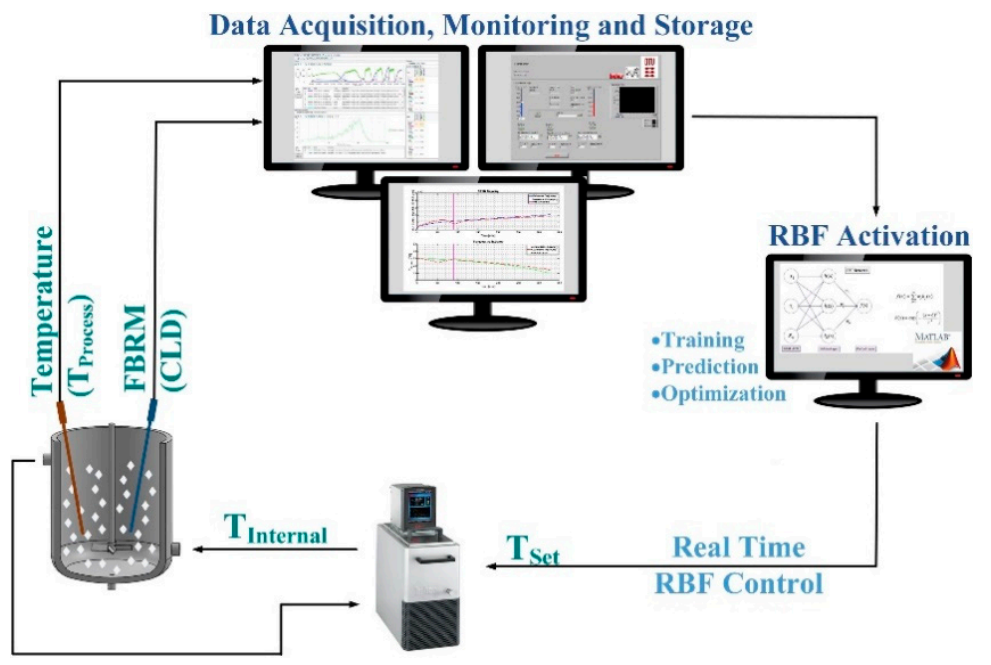

Figure 1. Robust control of crystallization process based on radial basis function (RBF) neural network. (Figure adapted from Reference [32], Copyright 2020, Elsevier).

\subsection{Supersaturation Control/Concentration Feedback Control}

With the development of ATR-FTIR and ATR-UV/Vis accurate in-situ concentration measurement methods, SSC/CFC can be applied to the cooling and dissolution of crystallization systems on laboratory and industrial scales. The advantage that the SSC control strategy can improve product quality has been widely reported in existing research [41,42].

For a typical batch cooling crystallization process, the method of concentration feedback control is shown in Figure 2 [2]. The controller calculates the current solution supersaturation according to the real-time measured concentration $\mathrm{C}(\mathrm{t})$ and temperature $\mathrm{T}(\mathrm{t})$ and the solubility data $\mathrm{C}_{\mathrm{sol}}(\mathrm{T})$, and adjusts the temperature in time according to the obtained supersaturation data to maintain the target overshoot in the phase diagram supersaturation setpoint $\left(\mathrm{S}_{\mathrm{SP}}(\mathrm{T})\right)$. The advantage of this method is that it can automatically determine the best operation trajectory in the time domain, such as the cooling curve, by specifying the operation trajectory in the crystal phase diagram, which can be implemented on the industrial scale through a standard tracking control system.

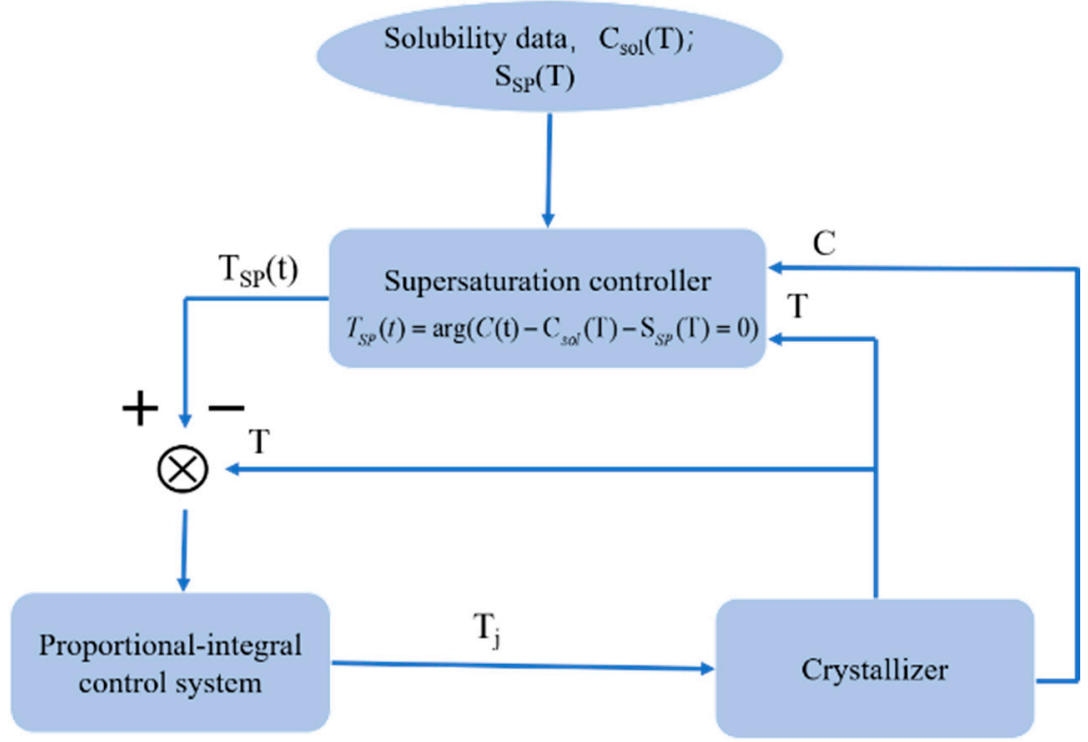

Figure 2. Generic block diagram of concentration feedback control approach.

According to Figure $3 a$, based on the measured solubility and nucleation metastable limit, the crystallization process needs to be controlled to follow an operating trajectory 
to avoid the uncertain nucleation zone. However, the crystallization process and the conventional control approaches are often sensitive to variations of process conditions, e.g., crystal attrition, agglomeration, accidental seeding, and impurities. SSC, also called concentration feedback control, is based on the strategy of controlling the crystallization nucleation and growth by following a targeted operating curve in the phase diagram through manipulating the operating temperature (or solvent/antisolvent ratio) [34,43]. The implementation of SSC requires the solubility of the compound and the real-time solute concentration during the crystallization process. In SSC, a supersaturation setpoint $\left(\mathrm{S}_{\mathrm{sp}}\right)$ is specified rather than a target concentration trajectory, and the supersaturation setpoint is fixed based on fundamental process understanding: metastable limit, solubility curves of different polymorphs, and other factors might also impact the decision. The main advantage of the SSC over uncontrolled crystallization is that the operating curve can be directly maintained within a "robust operating zone", which can represent the nucleation metastable zone or the targeted polymorph nucleation/growth region. In this way, SSC can avoid undesired nucleation and polymorph transformation and achieve optimal crystallization performance without considerable experiments for investigating the influence mechanism of process conditions [44-46]. The schematic representation of the SSC approach is shown in Figure $3 b$.

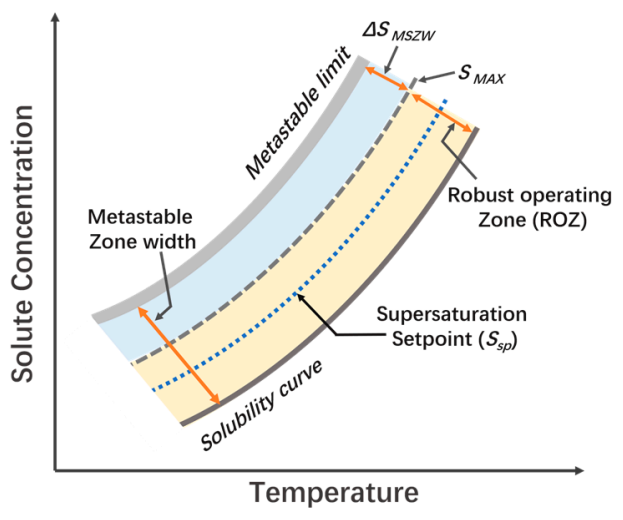

(a)

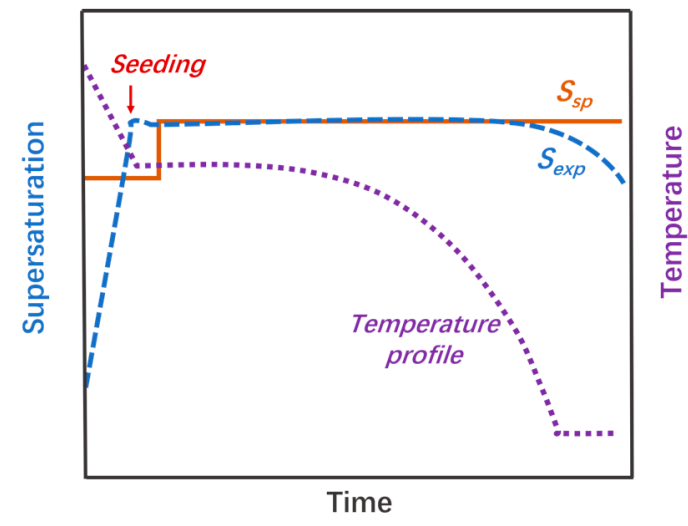

(b)

Figure 3. Crystallization phase diagram (a); supersaturation and corresponding temperature profiles obtained during the supersaturation control (SSC) process (b).

Supersaturation is the driving force for the crystallization process and many researchers have investigated various methods for supersaturation measurement and implementation of constant SSC strategy [31,46]. By using traditional open-loop control approaches to implement the cooling profile, such as simple linear cooling, it is hard to maintain the concentration operating curve along with an expected trajectory. The SSC is a higher-level control approach through controlling the crystallization operating trajectory rather than controlling the process by just following the timely determined temperature profile (or solvent/antisolvent ratio). Based on the real-time concentration measurement, SSC is also an adaptive control approach to deal with the kinetic variables of the crystallization process, thus a robust operation can be achieved within the metastable nucleation region where intensive nucleation does not happen and the supersaturation is consumed and controlled by crystal growth [47-49]. SSC has been widely applied in cooling and antisolvent crystallization systems at the laboratory as well as industrial scales, by which improved critical quality attributes have been extensively demonstrated $[3,43,50]$.

In the SSC framework for a batch cooling crystallization, the solution temperature is controlled from an initial value to a final point with varying cooling rates to achieve the desired concentration trajectory. Hence, by decreasing the temperature in a controlled manner, numerous important crystal properties can be manipulated, such as crystal shape 
and size distribution [51,52]. Moreover, because the operation curve in the phase diagram can be designed and controlled, the SSC strategy could be particularly used for polymorph control [13,40,53-56]. In recent years, the method of SSC has been developed mainly as part of various advanced control strategies for improving specific crystal attributes and process efficiency.

Applications of the SSC approach have also been achieved by many industrial companies, such as Merck Sharp \& Dohme Corp [57], Syngenta Crop Protection M€ unch Wilen AG on a 250 L scale [58], BASF SE [59], and Schering-Plough [2]. SSC is a model-free control approach but is calibration-based and the calibration model needs to be transferred from the laboratory into manufacturing capacities, which is generally a particular challenge for industrial implementation [60]. To alleviate this problem, a simplified SSC approach was proposed by using a simpler relationship between the solute concentration and the spectroscopic data, instead of a multivariate calibration model [61]. However, the SSC approach has been developed and applied mainly based on the batch cooling crystallization process, which is widely used in some scenarios, such as the crystallization of heat-sensitive materials and enantiotropic polymorphic crystallization systems [55,56,62,63].

\subsection{Direct Nucleation Control}

Controlling the crystallization process in the metastable zone is conducive to improving the stability of the process. This approach applies to most drug crystallization systems. However, if the system disturbance is relatively severe, for example, fine particles generated by particle breakage, changes in the quality of seed crystals, and changes in the metastable zone caused by fluctuations in raw material composition, etc., the robustness of the process will be greatly reduced. Therefore, many scholars have proposed some new model-free control strategies to weaken the impact of process disturbances, of which DNC is one of the very effective methods [64].

DNC aims to remove fine particles generated by secondary nucleation and allow the growth of the larger crystals. Secondary nucleation increases the number or counts, which can then be lowered by inducing particle dissolution. The real-time monitoring and control of the number of particles in the solution realizes the control of the crystallization process. The DNC approach was developed to directly improve the CSD of the solid product by controlled temperature cycles (or antisolvent/solvent alternate addition) that allow the crystallization metastable zone boundaries to be crossed repeatedly [64]. In the original DNC strategy, based on the understanding that the lower number leads to the larger mean size of the particles with certain output, the crystal counts number per second measured by FBRM is maintained as setpoint and then it can be controlled by successive dissolution (by heating or solvent addition) and supersaturation generation (by cooling or antisolvent addition) [65]. The setpoint of particle counts and the cooling/heating rate (or antisolvent/solvent addition rate) are needed to be identified by preliminary experimental investigation. The control loop of the DNC strategy is shown in Figure 4 [2].

Compared with other model-free control strategies, the most significant feature of direct nucleation control is the ability to directly monitor and control the crystal properties, which can be achieved through a controlled growth and dissolution cycle (cooling/heating cycle or anti-solvent/solvent addition cycle). There are many advantages of this modelfree approach reported for the crystallization production: better CSD and larger mean size of product [66,67], enhancement of crystal surface quality [68], decreased solvent inclusion [69], and so on. In addition, direct nucleation control can repeatedly achieve crystal surface dissolution and regrowth, which can reduce the embedding of impurity molecules in the crystal lattice to improve product purity, and can also repair crystal surface defects [68]. Additionally, the DNC method can also detect the information of the solubility and nucleation lines, thus it is adaptive and robust for crystallization scale-up without prior study on the crystallization model and kinetics. 


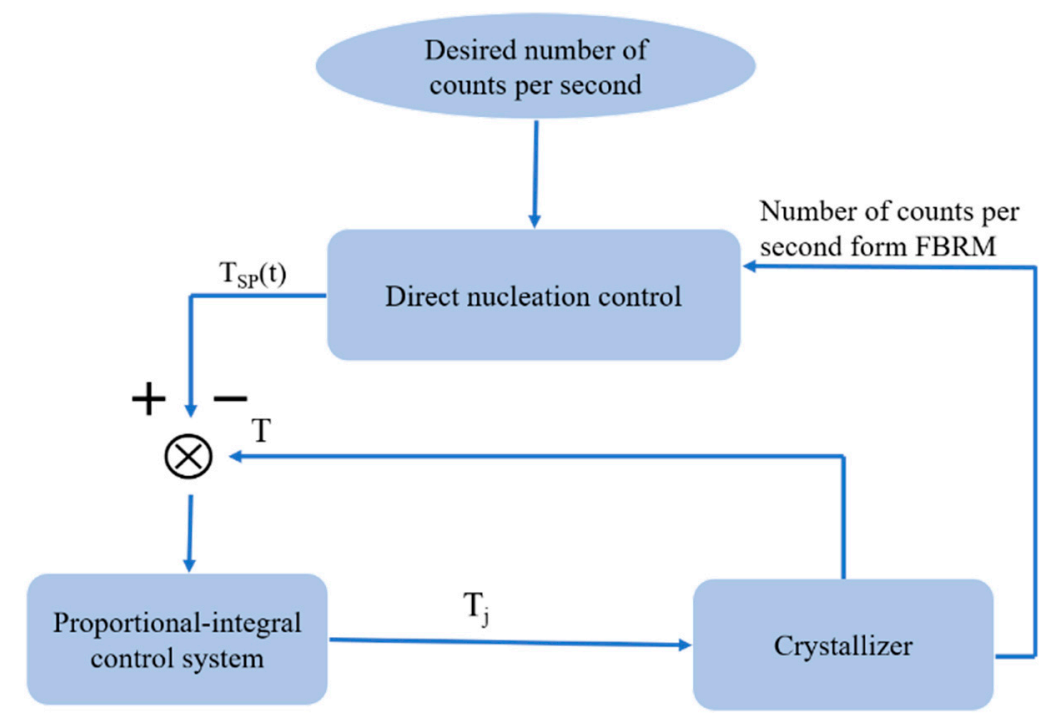

Figure 4. Control loop of the direct nucleation control strategy.

Because of the control of the crystal number the DNC is a robust feedback control strategy. When the number of monitored crystals changes, DNC automatically adjusts the operating conditions, which can well overcome the adverse effects of process disturbances. The DNC strategy is applied to the scale-up of the paracetamol cooling crystallization process. At a production scale of $100 \mathrm{~L}$, the properties of paracetamol crystals in different batches during the scale-up process are similar, which proves that the direct nucleation control strategy can be well applied to the crystallization process scale-up [65]. In addition, DNC has a good application in controlling the particle size and size distribution in the process of antisolvent crystallization. Ostergaard et al. used the DNC strategy to obtain the desired solid morphology in a ternary solvent and antisolvent system [70].

Direct nucleation control strategies are gradually applied to various crystallization processes and have been integrated into commercial software packages such as CryPRINS and CryMOCO. The traditional direct nucleation control strategy is based on the particle number information provided by FBRM. However, other properties of the crystal can also be applied to the control algorithm. Therefore, the use of other PAT tools (such as image analysis techniques) to design the growth-dissolution cycle to achieve more precise process control is a development trend of direct nucleation control strategies [65].

\subsection{Image Analysis Based Feedback Control}

Digital imaging technology is a rapidly developing technology in industries such as the food industry. Dynamic image analysis (DIA) has also been successfully used in the pharmaceutical industry. Image analysis is also used to measure the residence time distribution of compression and granulation processes, which is becoming more and more widespread in the pharmaceutical industry [71,72]. Based on the extension of the mass flow measurement principle, Madarász et al. [73] created a novel quality measurement system based on image analysis for online measurement of particle size and particle mass flow. The system can capture the image of the feed powder and analyze it in real-time to determine the mass flow rate and the particle size of the free-falling particles; it can also be used for process feedback control to achieve mass flow control by controlling the feeder screw speed. Sayin et al. [74] found that DIA is a promising method for monitoring continuous twinscrew wet granulation. In addition, DIA has been successfully applied to feedback control of batch crystallization [37] and high-shear batch granulation [75]. Madarász et al. [73] established an online particle size analysis tool for continuous wet granulation based on DIA, which realized real-time feedback control of the process by controlling the liquid feed rate. For the real-time monitoring of the crystallization performance, the DIA techniques are suitable for the monitoring and control of crystal shapes. Mazzotti et al. [76-79] used 
the stereoscopic imaging device $\mu$-DISCO to provide information such as particle size and shape distribution (PSSD) and solute concentration to the feedback controller to control the shape and size distribution of needle-like crystals. Borsos et al. [37] used PVM technology to achieve real-time monitoring and open-loop crystal aspect ratio (AR) control. In fact, image processing technology is rapidly spreading, and IA-DNC was developed based on PVM. The images collected by PVM are processed in real-time, and information such as the particle size, shape, and relative particle number (counts/s) of the IA-DNC is extracted for particle analysis.

The L-ascorbic acid crystallization process and results are shown in Figure 5 [37]. It can be seen that IA-DNC can successfully control the size distribution of crystals, which provides an alternative method for the FBRM based DNC to control the number of particles or other shape related crystal properties more directly.

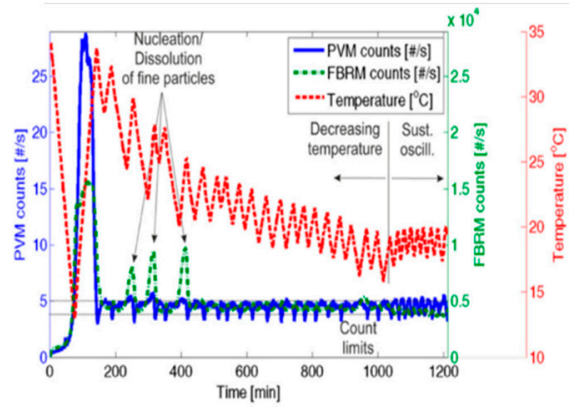

(a)

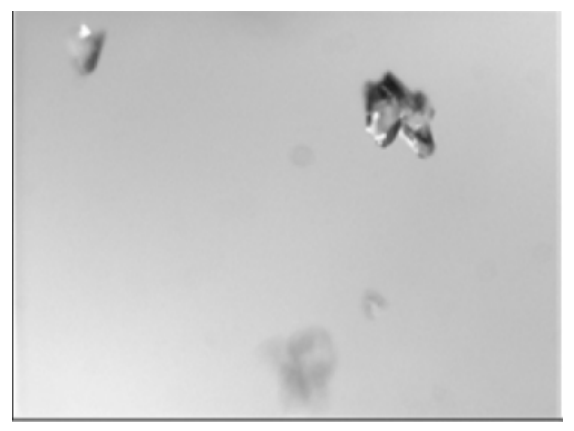

(c)

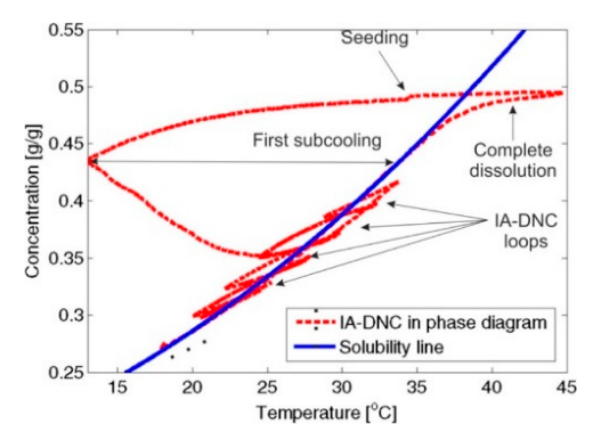

(b)

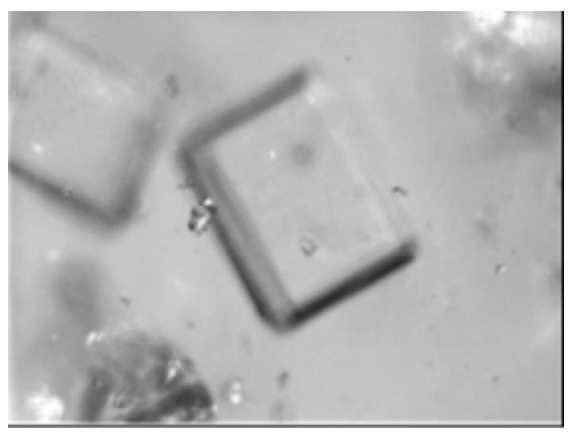

(d)

Figure 5. Temperature, focused beam reflectance measurement (FBRM) counts per second, and concentration profiles overtime during an image analysis based direct nucleation control (IA-DNC) experiment (a); a corresponding operating curve in the crystallization phase diagram (b); PVM images during the first nucleation process (c); in-situ particle vision and measurement (PVM) picture of product crystals from the IA-DNC experiments (d). (Caption and figure reprinted with permission from Reference [37]).

When FBRM is used for crystallization monitoring of high aspect ratio crystals, since the probability of capturing the crystal width is greater than the probability of capturing the crystal length, the FBRM count will show an increase in the number of thin chord lengths. The changes in the chord length of the crystallization process will be interpreted as a nucleation event, and FBRM-based DNC will trigger dissolution, resulting in a size reduction. In these cases, FBRM-based DNC often results in continuous circulation and long batches without eventually converging to the final required temperature. The key advantage of IA-DNC is that the measurement of the number of particles is completely unaffected by the shape of the crystal and is a true reflection of the nucleation or dissolution of the crystal. IA-DNC also has certain limitations. High solids concentration can cause crystals to overlap, which reduces the chance of capturing a single crystal. When the 
particle size in the agglomerates is below the limit of the detectable size of the object, PVM will not detect these fine powders.

Besides the monitoring and control of crystal shape, IA-DNC is also suitable for controlling the crystallization of easily agglomerated materials. By comparing the counts provided by FBRM and PVM, it can be observed that PVM with a given IA setting (usually used to avoid noise in the image) does not detect the granularity from clump collapse. In this case, the FBRM count behaves as an inverse response system, which is detrimental to process control and can cause a large amount of oscillation. The advantage of counting PVM compared to FBRM is very obvious. Signal artifacts caused by sticking can be easily corrected in image processing. The inverse response of the FBRM count during the heating phase (due to the decomposition of aggregates) does not appear in the PVM count. In the case of high aspect ratio (AR) crystals, counting based on image processing is usually more reliable. PVM can also provide shape information, which can make IA-DNC suitable for model-free feedback control of shape. IA-DNC produced fewer agglomerated crystals, indicating that IA-based DNC can also be used for real-time shape control.

\subsection{Polymorphic Feedback Control}

Raman can identify different crystal forms, and online Raman can monitor the polymorphism in solution in real-time. The feedback control strategy based on Raman spectroscopy has been reported in order to generate the desired polymorphic form $[2,65,80]$. Hirsch et al. [81] established feedback control in the lactose hydrolysis reaction based on Raman, and the results were good considering the simplicity and short time frame of preparation. Pataki et al. [82] established feedback control based on the ratio of the characteristic peak intensities of the two crystal forms of carvedilol measured by Raman, and successfully prepared the crystal form II. Although the comprehensive application of various process analysis techniques can simultaneously monitor multiple aspects of the crystallization process, the information obtained is rarely able to be combined for real-time decision-making or control. Recently, research scholars have proposed a combined control method to analyze various signals in the crystallization process and automatically determine the most relevant signal combination and control target for a specific process [36]. The complementarity and redundancy of the obtained information made the robust crystallization control strategy able to be realized.

Tacsi et al. [36] developed a new, easily performable feedback control of crystallization based on the exact polymorphic concentration (mass ratio of polymorph/solvent). Through real-time monitoring of the polymorphism in solution by Raman, there is also the auxiliary role of UV/Vis in this process. As shown in Figure 6, the polymorphic concentration is obtained by calculating the current solid-phase concentration from UV/Vis data, and then the value is proportional to the Raman spectral concentration of different polymorphs. Real-time evaluation of Raman spectroscopy and UV/vis spectroscopy is carried out with the help of the Matlab program. The calculated polymorph concentration uses a programmable logic controller to control the cooling and reheating cycles of the crystal. The high temperature will dissolve the crystals in the solution, and the decrease in temperature will facilitate the nucleation and growth of crystals. It is detected that the concentration of the non-target crystal form is greater than the set value and lasts for a certain time, and the heating cycle will start to dissolve. When the concentration of the target crystal form is greater than the set value and the concentration of the non-target crystal form is less than the set value for a certain period, the control strategy would continue the cooling to proceed with the crystallization process.

The dynamic changes of process parameters and crystalline phase diagram in the PCC process of carvedilol are shown in Figures 7 and 8. Regardless of whether the target crystal form is crystal form I or crystal form II, the PCC can effectively produce the target crystal form. During the crystallization process, if the no-target crystals exist in the crystallization system, the PCC will start a control program to increase the temperature to the dissolution temperature, and then perform crystal form purification to prepare the target crystal form. 


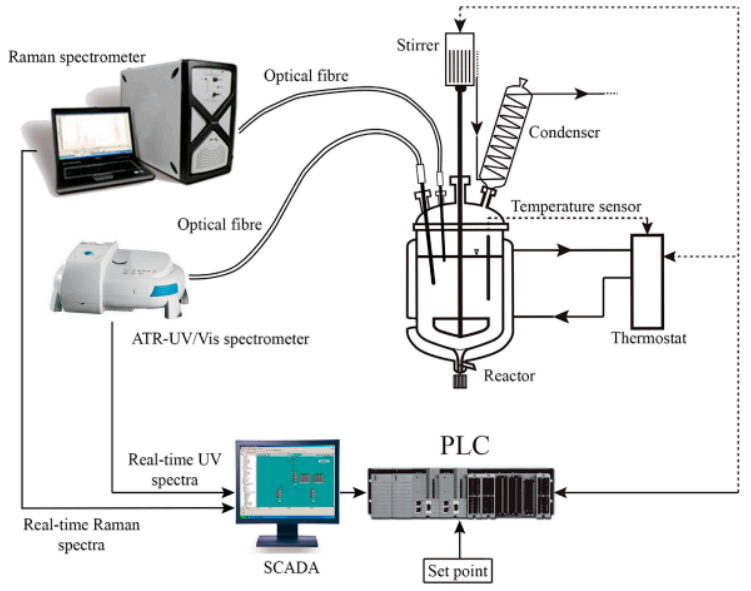

(a)

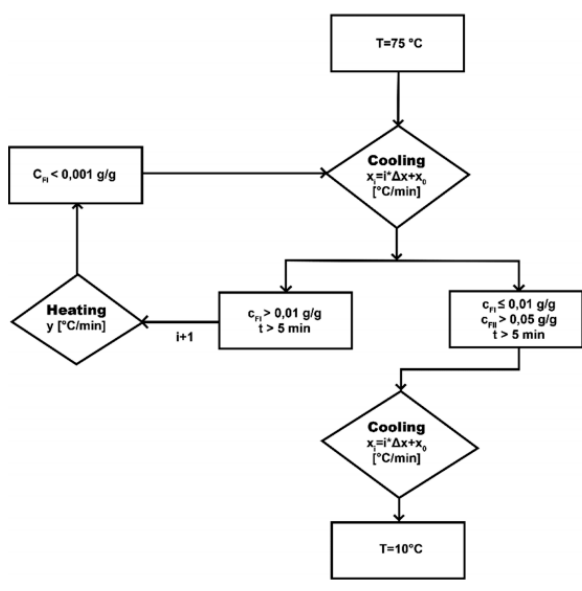

(b)

Figure 6. Schematic diagram of the experimental setup (a); the detailed strategy of the feedback control (b). (Caption and figure reprinted with permission from Refrence [36]).

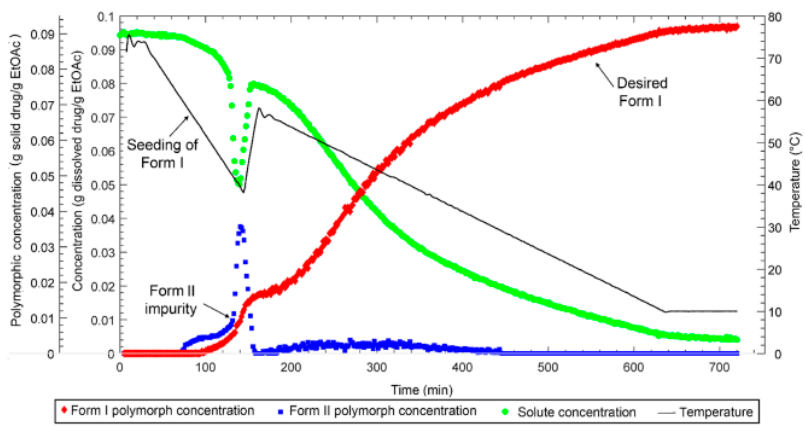

(a)

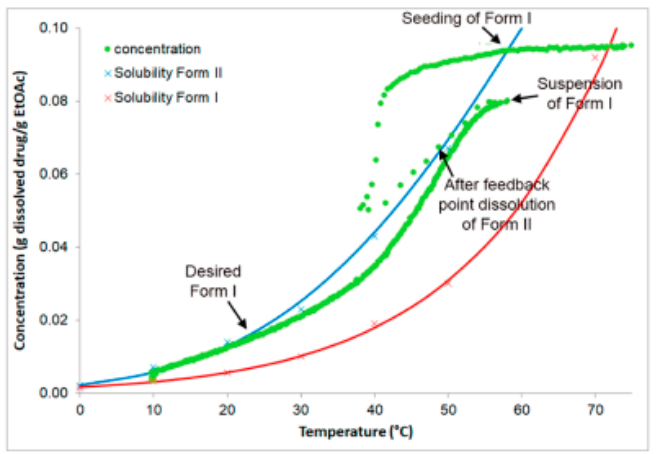

(b)

Figure 7. The target crystal form is Form I: concentration and temperature profiles (a); crystallization phase diagram during the polymorph concentration control (PCC) process (b). (Caption and figure reprinted with permission from Reference [36]).

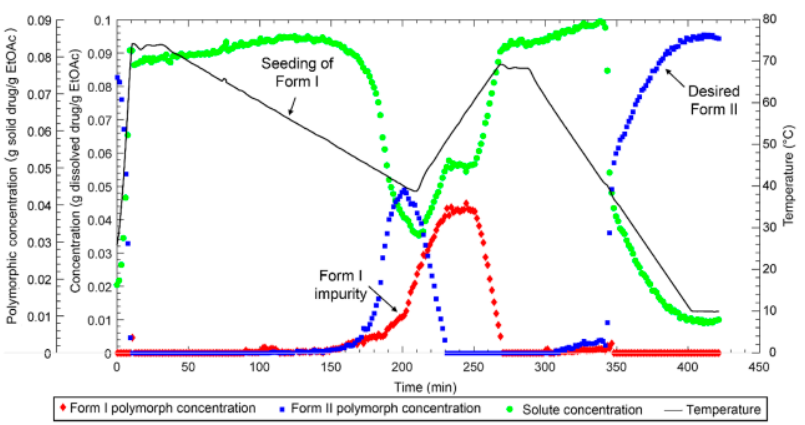

(a)

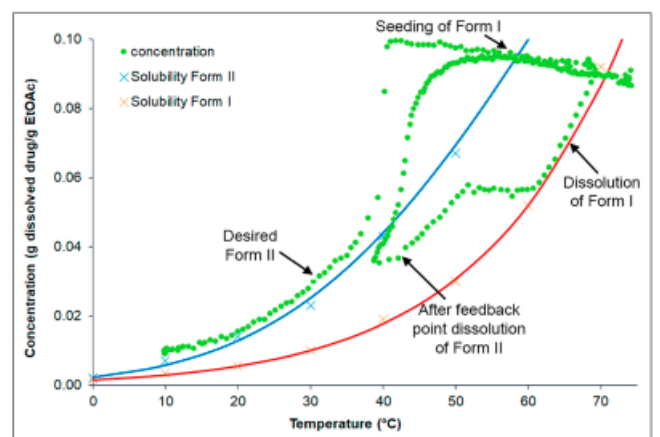

(b)

Figure 8. The target crystal form is Form II: concentration and temperature profiles (a); crystallization phase diagram during the PCC process (b). (Caption and figure reprinted with permission from Reference [36]).

PCC is a control method that uses combined Raman and ATR-UV/Vis spectroscopy to produce metastable polymorphic forms of selected model drugs. PCC can always be performed at the same concentration level, so it provides a reliable and stable PAT solution for the crystallization of any pure polymorph. The system only needs to be heated to dissolve in an undesirable form, so it provides a more economical control strategy than the 
previously announced control based on Raman intensity. Besides, PCC is a potential control strategy to crystallize predefined polycrystalline components through cooling control.

Based on the combination of Raman spectroscopy and ATR-UV/Visible spectroscopy, Simone et al. $[40,83]$ developed active polymorphic feedback control (AFPC) and used it to perform hierarchical control to achieve crystal refining, as shown in the simple schematic diagram of the control strategy (Figure 9). Raman spectroscopy is used to detect the presence of the undesired form $(\mathrm{P})$ by using a calibration-free approach; ATR-UV/Vis is used to measure the solute concentration (C) and performs SSC using a calibrationbased approach to determine the set point for the temperature controller $\left(\mathrm{T}_{\mathrm{sp}}\right)$. In the feedback control strategy, the Raman signal is used to detect the presence/dissolution of polycrystalline pollutants, and the APFC method will automatically determine the dissolution period needed to eliminate the pollutants. After the purity correction step based on the Raman signal, the supersaturation control is adopted to follow the working curve between the solubility curve of the stable and metastable polymorphs in the phase diagram so as to avoid further pollution of the metastable form.

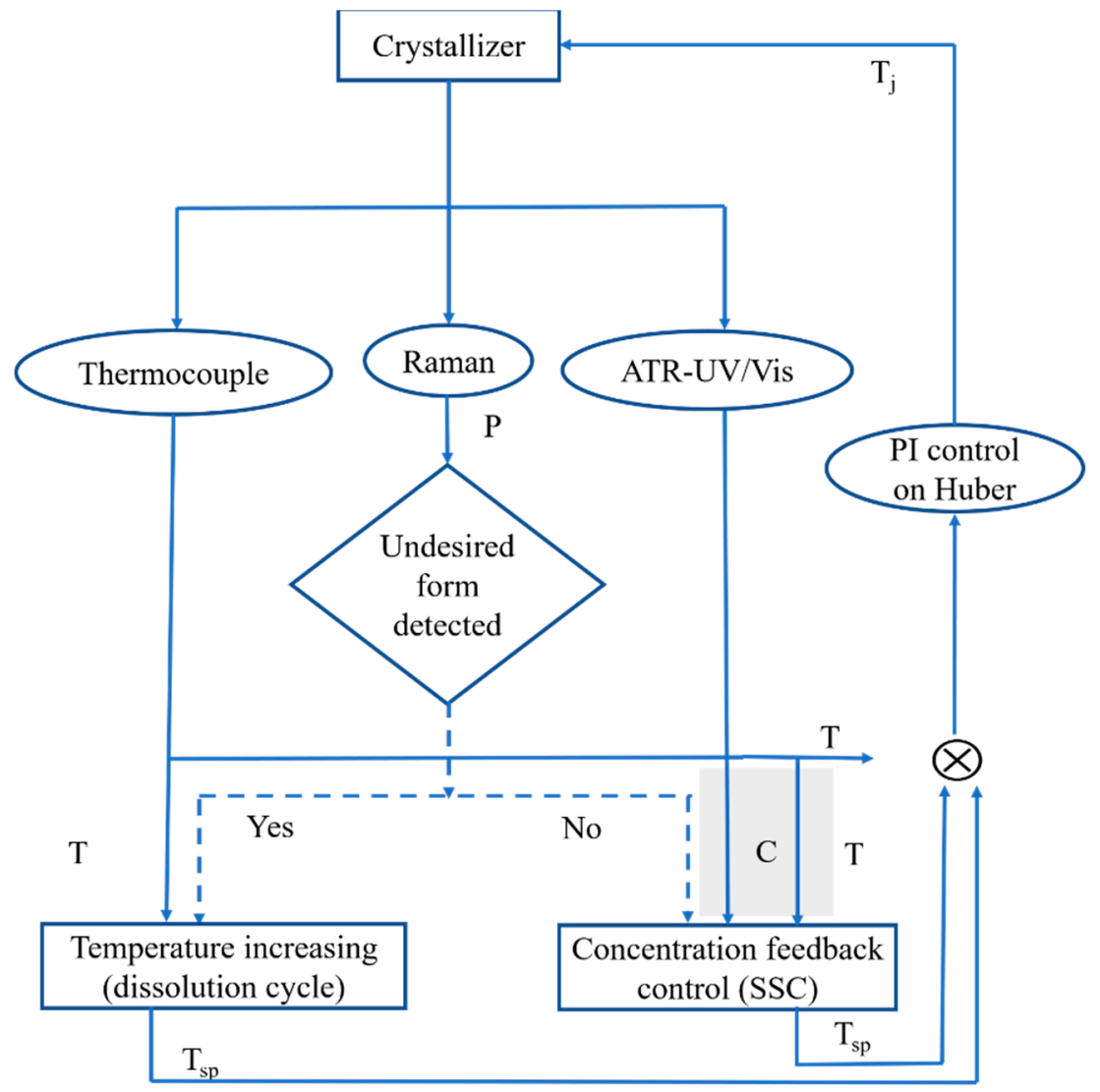

Figure 9. Schematic of the active polymorphic feedback control (APFC) approach for polymorphic control.

The APFC method was evaluated by using o-aminobenzoic acid (OABA) as a model system. Figure 10 shows the experimental results when using seeds composed of type I and type II mixtures (simulating a contaminated seed). After the crystals are completely dissolved, the solution is cooled to slightly above the solubility of form II so that the system is supersaturated with respect to both polymorphic forms. The total count/second and the two Raman signals (for forms I and II) increase when the seed mixture is added. The crystals also started to grow/nucleate immediately, because the solution was supersaturated for both forms, as shown by the rapid decrease in concentration. If the Raman spectroscopy detected form II, the APFC changed from cooling to heating mode. Heating continues until the Raman signal of form II stabilizes at the same level as the solution (which means that 
form II is completely dissolved), then the strategy switches to automatic supersaturation control, setting a setpoint between the solubility curves of the two form points. The supersaturation control method automatically calculates the temperature curve required to maintain a constant supersaturation.
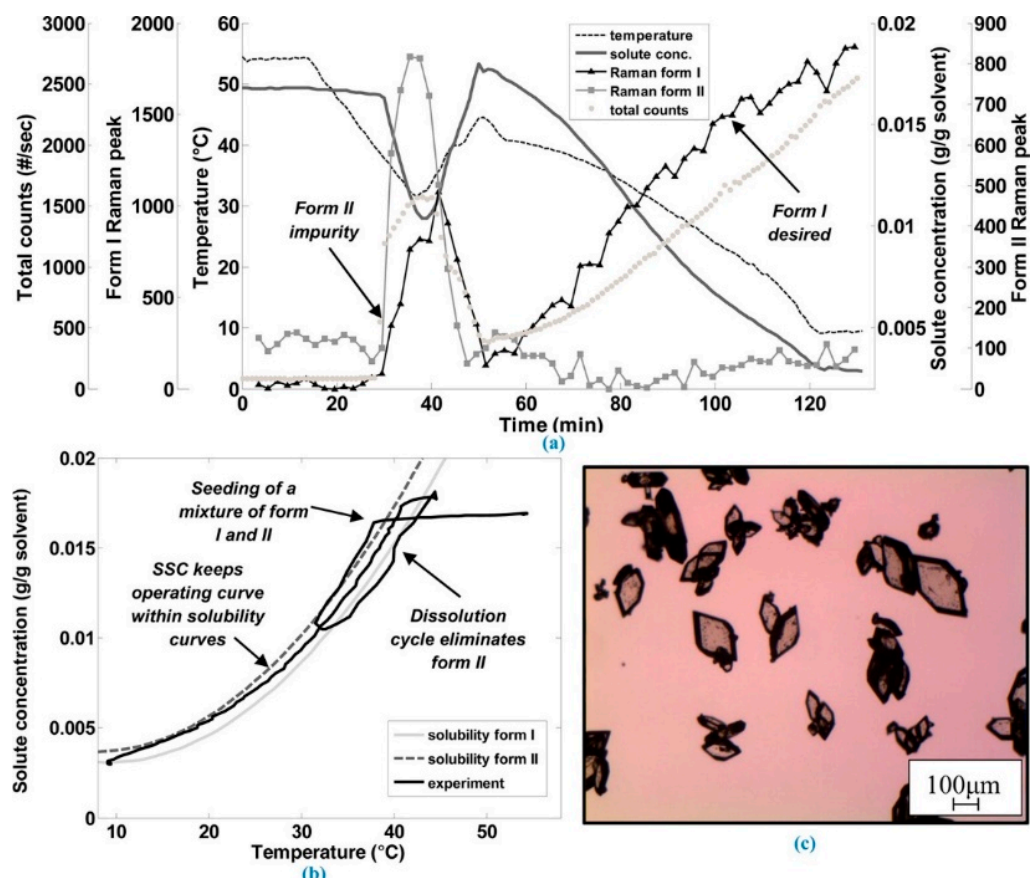

Figure 10. Time evolution of temperature, concentration, Raman signals for forms I and II, and total counts/s from FBRM (a); an operating curve in the phase diagram (b); microscope image of the resulted dried crystals indicating only the presence of form I with no trace of needle-shaped form II crystals in the product (c). (Caption and figure reprinted with permission from Reference [40]).

The APFC method is a highly robust adaptive control strategy that can automatically determine the on/off of the dissolution loop, which can eliminate the changes due to changes in the nucleus composition or polycrystalline impurities in the seed crystal (for example, due to the previous batch or the following particle processing, such as milling or drying). Although this method has proven to be used to produce and control pure polymorphs, it can also be used to produce a desired polymorphic mixture. Additionally, the method can also be extended to a solvent-resistant or combined cooling and solventresistant system.

\subsection{The Mass-Count Framework}

In the cooling crystallization process, the temperature is the only control variable: how to control it to obtain specific product characteristics may be complicated. That is to say, the change of temperature with time controls the driving force of crystallization, which affects crystal nucleation, growth, dissolution activity, reunion, and fragmentation, and these potential phenomena together determine the number and properties of the crystals produced. Some research scholars have established the population balance framework for process control $[84,85]$. The population balance framework is stimulating in concept and complete in mathematics and has been widely used now. This modeling strategy has shortcomings during the application. For example, it is not conducive to establishing feedback control due to the limitations of current sensors and computing power. However, the use of feedback is especially advantageous for controlling the outcome of a complex dynamic process. Griffin et al. [86] used ART-FTIR and FBRM to expand the mass-count (MC) framework. The feedback control strategy established according to the MC framework has two major applications: controlling solution crystallization (to produce crystals of the 
required size) $[39,86,87]$, and controlling colloidal assembly (to produce perfect colloidal crystals) $[88,89]$. Figure 11 shows the four key attributes of PAT online measurement. Temperature and supersaturation are solution-state properties that can be manipulated; the crystal mass and chord count are used to characterize the aggregate properties of the crystal state.

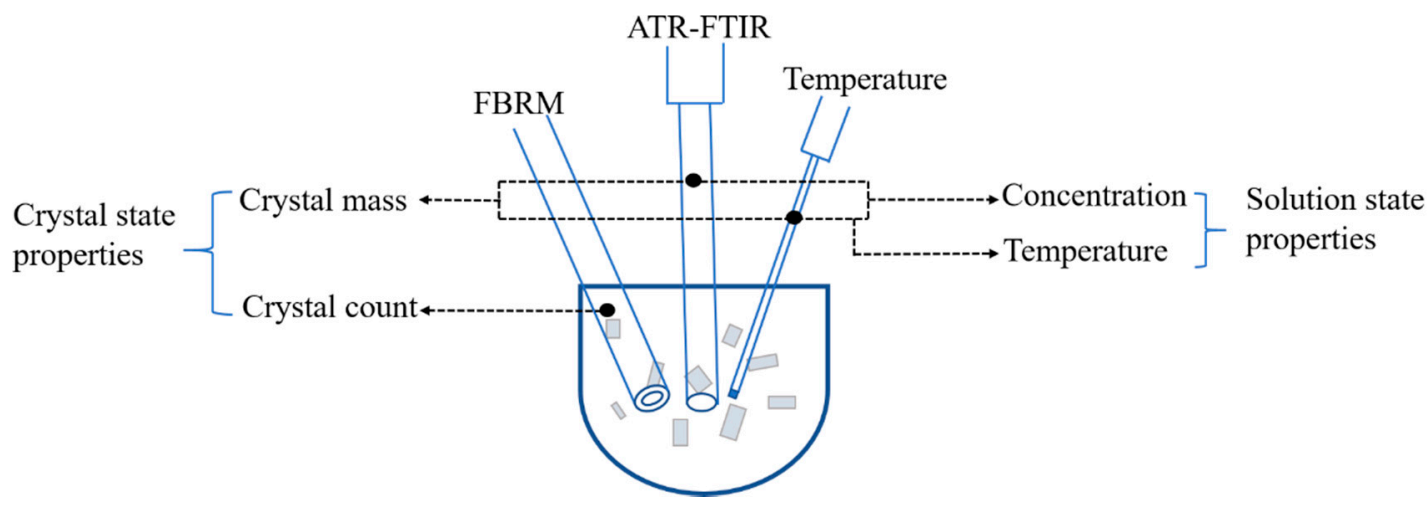

Figure 11. Measurements made online with PAT instruments.

Figure 12 shows the central attributes of the MC plots. When using this type of plot, the crystallization and dissolution kinetics can be seen as a movement in space: nucleation leads to an increase in the number of crystals without a significant increase in the mass of the crystal, resulting in a movement to the right; growth results in upward movement; finally, dissolution leads to a decrease in mass and count, which leads to downward and leftward movements. A rule-based control policy is shown in Figure 12; the crystal state in the solution is at different positions to initiate different cooling rates or heating.

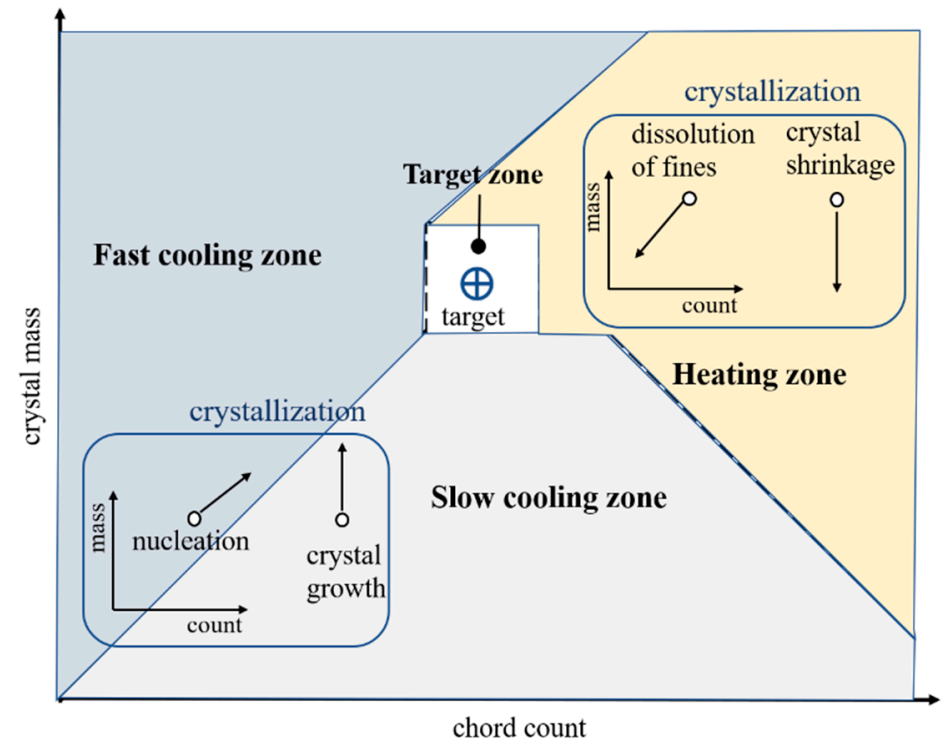

Figure 12. Crystallization and dissolution dynamics illustrated as the movement in mass-count (MC) space and rule-based feedback control policy.

The model-based control and rule-based control results are shown in Figure 12. From Figure 13a, it is seen that the model-based strategy controls the MC trajectory by applying complex temperature distributions to reach positions close to each target position in the MC space. The model-based control strategy at times employed supersaturation control and at other times applied temperature cycles. Figure 13b shows that the temperature trajectory is slightly simpler under rule-based control, and the temperature cycle is applied 
to reach the target position. The number of particles in the solution was monitored by FBRM, the solubility data and the concentration information of the solution monitored by ART-FTIR were used to calculate the solid mass. The temperature was raised to dissolve the fine particles to reduce the number of particles in the solution when the number of particles is greater than the set value. On the contrary, the cooling program was started to promote nucleation and increase the number of particles when its value was less than the set one. The particle mass was almost always less than the set value during the whole experiment, so there was no need to dissolve the solid mass by heating. In any case, the final results of the two strategies are almost the same: for each test run, the final mass count position is controlled near the target position. Therefore, the control strategy can stably control the quantity and mass of the crystal.

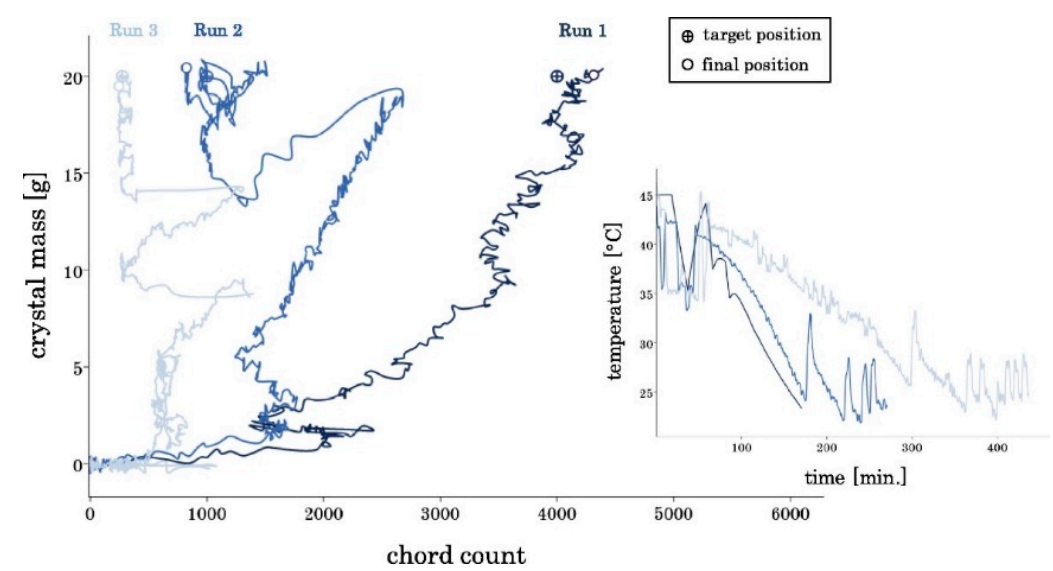

(a)

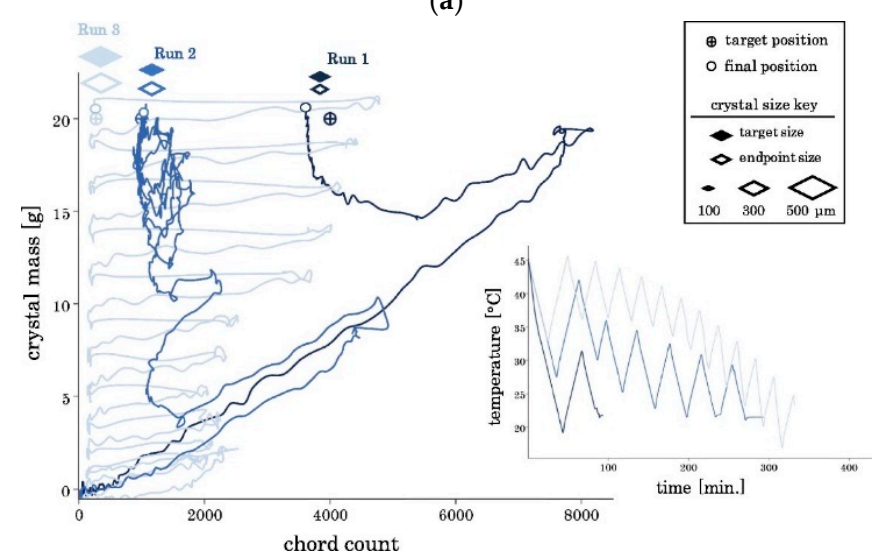

(b)

Figure 13. Model-based control results (a); Rule-based control results (b). Summary of the masscount trajectories achieved with the given feedback control scheme. For each target, the measured mass-average crystal size is shown visually against the target size. Inset: implemented temperature profiles. (Caption and figure reprinted with permission from Reference [39]).

Model-based and rule-based strategies are different but the results show that both can be used effectively. The crystallization and dissolution kinetics revealed by the MC framework can be quantitatively determined. The multiple different $\mathrm{MC}$ feedback strategies can improve the robustness of controlling the average crystal size in the existence of disturbances.

\section{Applications of Feedback Control in Crystallization}

Modern pharmaceutical manufacture has put forward higher quality requirements for product engineering, which needs to increase the yield and purity as much as possible, ensuring the consistency of crystal products in terms of particle size, crystal shape, crystal 
type, and chirality, and avoiding particle agglomeration and solvent entrapment [90,91]. However, crystallization process parameters may have a significant impact on the quality attributes of crystalline products, such as purity, morphology, size, polymorphs, impurity, dissolution rate, etc. [4-7]. Each or all of these quality attributes can independently or collectively affect the dissolution, bioavailability, efficacy, and safety of the drug in some cases [92]. Process control technology plays an increasingly important role in it. Traditional open-loop control approaches in crystallization show less sensitivity to the process variations in the limited design space. An increasing number of studies in recent times highlighted the advantages of active control, which can not only enhance the operational efficiency but also achieve accurate control of target quality of crystallization product, through the integration of PAT tools and advanced control strategies.

\subsection{Polymorph Control}

Drug polymorphism refers to the formation of two or more different molecular assembly modes when the drug molecule crystallizes from solution [93]. For some drugs, crystal form is one of the important factors affecting clinical efficacy. Although the chemical components of different crystalline drugs are the same, the solubility, dissolution rate, and stability may be different, which leads to differences in bioavailability. When the crystal form changes, good drugs may become ineffective drugs or even poisons [6], so the control of polymorphs is of great significance for the quality control of pharmaceutical products. The stable crystal form usually exhibits a lower solubility and dissolution rate compared with the metastable crystal forms. If the solubility of the stable crystal form is much smaller than that of the metastable crystal form, which affects the efficacy, or the drug needs to reach the maximum concentration in the body quickly, the metastable crystal form with high solubility and dissolution rate is preferred as the final product [94]. The ultimate goal of drug polymorphism control is to obtain a "dominant drug crystal form", that is, to obtain a drug crystal form with the best overall effect of stability, clinical effect, and safety.

Solution crystallization feedback control is one of the most effective methods to achieve the refining of the target crystal form. Supersaturation is the driving force of crystallization. For polycrystalline materials, different ways to produce supersaturation may result in different crystal forms. Controlling the supersaturation to obtain the desired crystal form is to use the difference of solubility between metastable and stable crystal forms. Because the solubility of the stable crystal form is usually lower than that of the metastable crystal form, when the concentration of the solution is controlled between the solubility of the two crystal forms, the stable crystal form will be obtained, which is an effective method to screen the stable crystal form [95]. For example, it is particularly difficult to obtain $\beta$-aminobenzoic acid in solution crystallization as $\beta$-aminobenzoic acid easily undergoes phase transformation to $\alpha$-aminobenzoic acid in most solvents. Zhang et al. [96] used concentration feedback control to control the operating range between the solubility curves of the two crystal forms to achieve the control of the $\beta$-aminobenzoic acid crystal form. Controlling the secondary nucleation metastable region by the crystallization operation curve is an effective method to achieve polymorphic control. Kee et al. [56] used a concentration feedback control strategy to control the metastable crystal form $\alpha$ during the crystallization process of L-glutamic acid. In the initial stage of the crystallization process, the seed crystal of the target crystal form $\alpha$ was added, and the supersaturation level was preset by controlling the operation trajectory in the crystal phase diagram: the product obtained had almost no stable $\beta$ crystal form.

The temperature cycle during the crystallization process is beneficial to dissolve the metastable crystal form produced during the crystallization process. Pataki et al. [82] used Raman to detect non-target crystal forms in the crystallization process and trigger automatic heating to dissolve and eliminate metastable crystal forms. Tacsi et al. [36] adopted PCC to separately refine two crystal forms of carvedilol. During the crystallization process, Raman detected a non-target crystal form to trigger temperature-rising dissolution, and the products obtained were all target crystal forms. APFC realizes the refining of the 
stable crystal form of OABA in the case of impure seed crystal form. Raman detects that the metastable crystal form triggers heating and dissolution, and then the system performs supersaturation control to prepare stable crystals [40].

In the past 20 years, in situ monitoring of polymorphism in the crystallization process has developed rapidly, including online Raman [36], in situ XRD [97], in situ laser backscattering [98], and in-situ process image microscopy [99]. Although no technology can be applied to all solute-solvent systems for online monitoring of polymorphs, for most systems, at least one sensor technology can be used to monitor the transformation between different crystal forms [100]. In recent years, process detection and online analysis methods have been widely used in polymorphic selective crystallization processes. Based on this, the development of polymorphic feedback control (or closed-loop control) strategies has also made continuous progress.

\subsection{Purity Improvement}

For the pharmaceutical production process, the purity of the product is a crucial quality indicator. Impurities in the drug will reduce the efficacy and even have physiological toxicity. These impurities may be artificially added surfactants or additives, or they may be by-products or catalyst residues in the synthesis process, or they may come from the solvents used in the production process [101]. During the crystallization process, the explanation of impurities precipitation with crystals is divided into the following three mechanisms: (1) impurities are adsorbed on the surface of the crystal; (2) impurities are embedded inside the crystal lattice; (3) solvent entrapment [102]. The traditional method to improve the purity of crystal products is recrystallization, but it is a process at the expense of yield, which will make the production process more cumbersome. Therefore, in recent years, the in situ control of product purity based on the process control method to meet the requirements of crystal quality has been widely concerned by scholars.

Simone et al. [54] studied the effect of concentration feedback control and direct nucleation control on the product purity of the vitamin B12 crystallization process. The results show that concentration feedback control can reduce the particle size distribution of crystal products, it has no significant effect on the product purity, and in contrast, direct nucleation control can effectively improve the product purity. This is because the direct nucleation control can inhibit the adsorption of impurities on the crystal surface by repeatedly dissolving the growth cycle, and the fine particles and impurities on the crystal surface will dissolve continuously during the heating process. Thus, in the subsequent cooling process, crystal growth is promoted, and the crystal with a larger particle size has a smaller specific surface area, which reduces the adsorption of impurities on the surface, as shown in Figure 14. Also, Saleemi et al. [35] applied the direct nucleation control strategy to the cooling and crystallization process of AZD7009 and compared it with the traditional linear cooling. The results showed that the direct nucleation control strategy can reduce particle aggregation and solvent entrapment, and the products have higher purity, larger particle size, and more regular morphology.

Due to the advantages of being lower cost and easier to scale-up, batch cooling operation is recognized as the most commonly used crystallization design [47,103]. However, the applicability of batch cooling crystallization is limited in some special cases, such as the crystallization of heat-sensitive materials. Many organic substances will be degraded due to side reactions (such as hydrolysis) at high temperatures, and the degradation rate will increase with increasing temperature [35,54,104-108]. For the batch cooling feedback control of such compounds, degradation in the high-temperature stage cannot be avoided, which will hinder the product yield and purity of the crystal, and the degradation product can also act as a growth inhibitor, further slowing down the crystallization process and increasing the degradation process [105,106]. Zhang et al. [109] used a new type of semi-batch SSC to crystallize salicylic acid. During the experiment, the temperature was constant, and the supersaturation was kept constant by controlling the flow rate of the antisolvent. The results show that the new semi-batch SSC method can very effectively 
control the crystallization of heat-sensitive compounds and obtain higher purity and higher quality products.

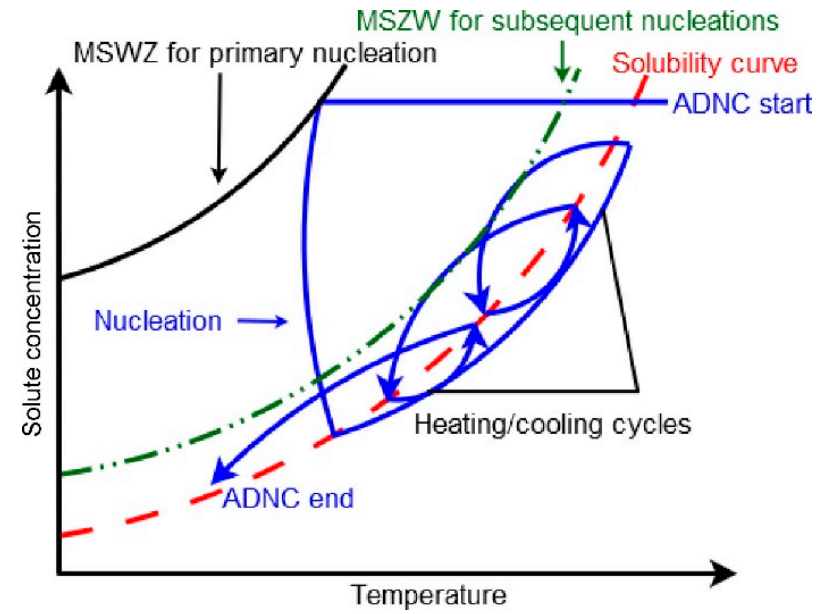

(a)

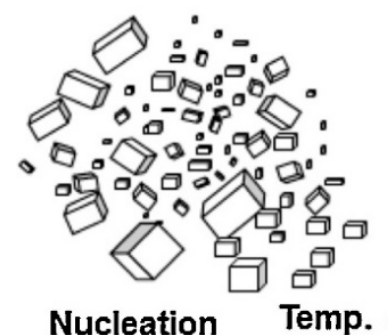

Nucleation

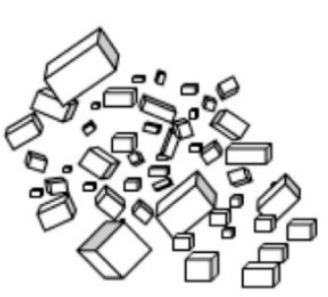

Temp. cycle 2

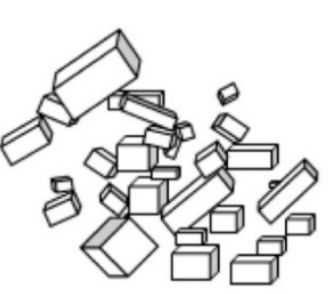

Temp. cycle 3
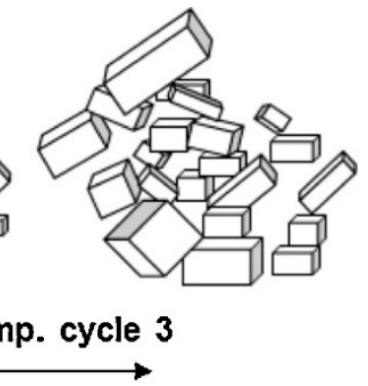

(b)

Figure 14. Schematic working of the automated direct nucleation control (ADNC) approach (a); Effect of temperature cycling on a crystal suspension (b). (Caption and figure reprinted with permission from Reference [35]).

At present, the realization of product purity control in the crystallization process based on PAT technology has not been applied on a large scale because there is still a lack of monitoring equipment for direct in situ analysis of impurity content. Generally, by improving the morphology and particle size distribution of the crystal, the impurities introduced by the adsorption of impurities on the crystal surface and the solvent encapsulation could be reduced. Besides, controlling the degradation of heat-sensitive substances and reducing impurities during the crystallization process is also a major direction for purity control. How to improve the purity and yield of the product at the same time is also an important research field in the crystallization process control.

\subsection{Crystal Morphology Control}

For crystal products obtained by crystallization, crystal shape is an important property, because it plays a vital role in determining the quality of the final product and the efficiency of downstream processes (such as filtration, washing, and drying). As pointed out by Lovette et al., [110] the required shape and crystal size distribution depend to a large extent on its application. For example, needle-shaped (i.e., high aspect ratio) crystals are generally unpopular due to processing difficulties [111]. Feedback control strategy for optimizing the crystal morphology of the products obtained in the crystallization process has been considered to be a challenging subject. On the one hand, the monitoring technology is limited; on the other hand, the crystal growth dynamics data are required for the crystal morphology control, and the modeling ability based on the crystal dynamics data is limited. 
In recent years, important progress has been made in the online monitoring of crystal morphology in the crystallization process. For online real-time measurement of crystal morphology, the most notable progress is the application of two-dimensional (2D) and threedimensional (3D) imaging techniques. These research advances have promoted the application of feedback control strategies in the field of crystal shape regulation. Yang et al. [112] used online wet grinding in combination with SSC and DNC to change the aspect ratio of needle-like crystals. The IA-DNC strategy developed based on PVM also has some applications in controlling crystal shape [37].

Model-free feedback control strategies have certain limitations in controlling crystal shape. In recent years, the online monitoring of crystal morphology during the crystallization process has continued to develop; the newly proposed multi-dimensional grain number balance model and its efficient numerical solution method have further deepened the understanding of the dynamic evolution process of the crystal group morphology [49]. These researches facilitate the application of model-based closed-loop feedback control strategies in the field of crystal shape control during crystallization. Majumder et al. [113] proposed a control device that manipulates the concentration of crystal growth modifier in the crystallizer to obtain the desired crystal shape. The simulation results showed that a simple feedback control configuration can manipulate the crystal growth modifier concentration to control the size and shape distribution of potassium dihydrogen phosphate crystals. Eisenschmidt et al. $[114,115]$ proposed optimal strategies for the control of supersaturation profiles as well as crystal size and shape by growth-dissolution cycles. Comprehensive simulation and experimental studies applied to this feedback control approach for the evolution of particle size and shape have also been reported to help to optimize the crystal morphology [76-79].

A closed-loop feedback control strategy could make the control of crystal morphology more accurate. For further improvement of the controlling of crystal shape, it still requires research on real-time monitoring methods including (1) 2D imaging probes and noninvasive imaging instruments for the crystal morphology online measurement, which needs the further improvement of image resolution and image segmentation accuracy, (2) The monitoring of high viscosity or high solid content systems is still extremely challenging, (3) There are still large deviations in the monitoring of acicular crystal shape, and the measured value of length direction in many cases will be smaller than the true value, and (4) Real-time multi-objective process optimization based on the multi-dimensional particle number balance model is more time-consuming, which requires the study of model calculation efficiency issues, such as through effective model reduction.

\subsection{Optimization of the Crystal Size Distribution}

The crystal size and CSD of the product have a great influence on its bulk density and fluidity, which strongly affect the efficiency of the downstream process (filtration, drying, granulation, and tablet pressing). In addition, controlling the particle size and particle size distribution of the crystal is also important for the final drug performance (shelf life, bioavailability, and dissolution rate) [116].

The control of crystal size and size distribution is directly affected by growth, nucleation, and dissolution. Generally, in a crystallization process, the growth process promotes crystal growth, the nucleation process will produce fine particles, and the dissolution process can eliminate fine crystals. The control of crystal size and size distribution is mainly through the control of crystal growth and nucleation. Most of the crystallization processes indirectly affect CSD through real-time temperature control or anti-solvent to follow the supersaturation set in the phase diagram $[3,117]$. Using the SSC strategy during the crystallization process can keep the supersaturation constant at the set value, and reduce or avoid secondary nucleation during the entire crystallization process to promote crystal growth. Compared with simple linear cooling, the SSC strategy could produce larger crystals and narrow crystal size distribution [54]. 
The DNC strategy was developed based on the idea that the smaller the system particles, the larger the product particle size, in which the temperature cycle is beneficial to eliminate fine crystals. Saleemi et al. [52] used the DNC strategy to automatically control the cooling-heating cycle during the crystallization process of paracetamol to obtain crystals with larger particle size and more uniform size. Nagy et al. [64] used the DNC strategy to control the CSD of glycine by controlling the addition of solvent and anti-solvent. The IA-DNC method based on image processing has a very significant effect on the control of particle size and particle size distribution [37]. The smaller the number of crystals at the crystallization endpoint, the larger the crystal size.

An important research field of particle size control in the crystallization process is to develop a more efficient and accurate real-time monitoring technology of particle size, which can effectively identify particle agglomeration and breakage. Moreover, the development of a deep understanding of the phenomenon of crystal agglomeration and the crushing process will also promote the progress of crystal size control in the crystallization process.

\section{Conclusions and Outlook}

Based on the current progress of pharmaceutical crystallization process control, this paper summarizes the important advances of industrial crystallization process control through process analysis technology and control strategy, and discusses the application of feedback control strategy for the improvement of purity, particle size, crystal shape, and crystal form in the perspective of product engineering. Although some progress has been achieved in the area of pharmaceutical crystallization process control, deeper research on complex systems, such as achieving simultaneous optimization of multi-objective including particle size distribution, specific crystal shape, and crystal form still needs to be conducted. For drugs with a high aspect ratio, it is difficult to prepare the required products by conventional temperature control or solvent antisolvent addition rate. Feedback control strategy combined with auxiliary equipment (such as ultrasound and wet grinding) has great potential to be constructed to control the switch and strength of auxiliary equipment in real-time.

In the rapidly developing biomedical industry, protein drugs are drawing more attention. The protein crystallization systems with negative apparent activation energies have been reported by numerous studies, and the crystallization rate may decrease with the increasing temperature during the crystallization process. There are other physical and chemical processes that also exhibit negative activation energies. For these systems, the semi-batch control strategy has some benefits over the batch operation. For example, for protein crystallization systems that present negative apparent growth activation energy, the crystal growth would be enhanced by using the semi-batch SSC operated at constant and low temperature.

Directly active control of polymorphs or pseudo-polymorphs can be performed by involving the signals of solid-state forms based on PAT tools, for example of Raman spectroscopy. A good calibration procedure for Raman spectroscopy is necessary to precisely determine the quantitative identification of solid suspensions. The calibration procedure for the PAT probe can be improved by the comprehensive analysis of the effects of various parameters, such as polymorphic purity, size and shape, solid density, and temperature, and the appropriate calibration experiments can be carried out based on the design of experiment work.

Drug chirality is also an important issue in the pharmaceutical industry. Plenty of cases have shown that the enantiomers present different bioactivities. Crystallization techniques have been widely used for chiral resolution, such as preferential crystallization and Viedma ripening, which are efficient because of the highly enantioselective crystalline phase. There are some similarities between the chiral resolution and the polymorph selection processes. The advanced polymorph control strategies can provide reference effects for the study of chiral resolution control. For example, a feedback control strategy can be developed for preferential crystallization of the active enantiomer based on Raman spectroscopy. 
Continuous manufacturing in the pharmaceutical industry is still in development and is preferred in practical application because of its high operation efficiency. The continuous implementation has also been achieved into the pilot and even industrial production after identification by the US Food and Drug Administration. Active control technology has been applied for the continuous production in the industrial manufacture of petrochemicals and bulk chemicals, while it develops a bit slower in the pharmaceutical industry because of the limited production scale and challenging technology transition. With the PAT developing and applied widely, along with the understanding of the concept of $\mathrm{QbC}$, the active process control strategy has started to be employed in the pharmaceutical continuous production. Active process control for the continuous crystallization process is also a promising and meaningful research direction. For instance, the semi-batch SSC can be applied in the start-up stage of the mixed-suspension mixed-product removal (MSMPR) continuous crystallization process, which can reach the steady-state faster and enhance operational efficiency.

Further, a multi-process coupling intelligent control system including crystallization, granulation, tableting, and other processes can be developed. Besides the fundamental logical framework and traditional PID control algorithm, the intelligent control system also requires the use of sensor technology, vision technology, big data, etc. to establish an intelligent monitoring system to monitor the state and properties of materials in real-time; use the Internet technology to collect and feedback process information in real-time, and finally, achieve process intelligence chemical manufacturing. Based on the development of PAT and information collection technology, the crystallization process control will usher in a broader development and application space, and it will play a vital role in realizing the intelligent manufacturing of fine or specialty chemicals including pharmaceutical products.

Author Contributions: Conceptualization, Y.G.; methodology, T.Z. and Y.M.; writing-review and editing, F.X. and Z.G.; visualization, B.H. and J.G.; funding acquisition, Z.G. and J.G. All authors have read and agreed to the published version of the manuscript.

Funding: This work was financially supported by the National Natural Science Foundation of China 21938009, 21676179, and 22008173.

Institutional Review Board Statement: Not applicable.

Informed Consent Statement: Not applicable.

Data Availability Statement: Not applicable.

Conflicts of Interest: The authors declare no conflict of interest.

$\begin{array}{ll}\text { Abbreviations } \\ \text { PAT } & \text { process analysis technology } \\ \text { CPPs } & \begin{array}{l}\text { critical process parameters } \\ \text { QbD }\end{array} \\ \text { quality-by-design } \\ \text { QbC } & \text { quality-by-control } \\ \text { ART-FTIR } & \text { Fourier transformed infrared spectroscopy } \\ \text { UV/Vis } & \text { ultraviolet-visible spectroscopy } \\ \text { PVM } & \text { particle vision and measurement } \\ \text { FBRM } & \text { focused beam reflectance measurement } \\ \text { PID } & \text { proportional-integral-derivative } \\ \text { ANN } & \text { artificial neural networks } \\ \text { RBF } & \text { radial basis function } \\ \text { SSC } & \text { supersaturation control } \\ \text { CFC } & \text { concentration feedback control } \\ \text { DNC } & \text { direct nucleation control } \\ \text { PCC } & \text { polymorph concentration control } \\ \text { IA-DNC } & \text { image analysis based direct nucleation control } \\ \text { MC } & \text { mass-count }\end{array}$




$\begin{array}{ll}\text { APFC } & \text { active polymorphic feedback control } \\ \text { CSD } & \text { crystal size distribution } \\ \text { DIA } & \text { dynamic image analysis } \\ \text { AR } & \text { aspect ratio } \\ \text { OABA } & \text { o-aminobenzoic acid } \\ \text { ADNC } & \text { automated direct nucleation control } \\ \text { MSMPR } & \text { mixed-suspension mixed-product removal }\end{array}$

\section{References}

1. Gao, Z.; Rohani, S.; Gong, J.; Wang, J. Recent developments in the crystallization process: Toward the pharmaceutical industry. Engineering 2017, 3, 343-353. [CrossRef]

2. Nagy, Z.K.; Fevotte, G.; Kramer, H.; Simon, L.L. Recent advances in the monitoring, modelling and control of crystallization systems. Chem. Eng. Res. Des. 2013, 91, 1903-1922. [CrossRef]

3. Braatz, R.D. Advanced control of crystallization processes. Annu. Rev. Control 2002, 26, 87-99. [CrossRef]

4. Mangin, D.; Puel, F.; Veesler, S. Polymorphism in Processes of Crystallization in Solution: A Practical Review. Org. Process Res. Dev. 2009, 13, 1241-1253. [CrossRef]

5. Kitamura, M.; Hara, T.; Takimoto-Kamimura, M. Solvent Effect on Polymorphism in Crystallization of BPT Propyl Ester. Cryst. Growth Des. 2006, 6, 1945-1950. [CrossRef]

6. Chieng, N.; Rades, T.; Aaltonen, J. An overview of recent studies on the analysis of pharmaceutical polymorphs. J. Pharm. Biomed. Anal. 2011, 55, 618-644. [CrossRef]

7. Bernstein, J. Polymorphism-A perspective. Cryst. Growth Des. 2011, 11, 632-650. [CrossRef]

8. Kadam, S.S.; Van Der Windt, E.; Daudey, P.J.; Kramer, H.J.M. A Comparative Study of ATR-FTIR and FT-NIR Spectroscopy for In-Situ Concentration Monitoring during Batch Cooling Crystallization Processes. Cryst. Growth Des. 2010, 10, 2629-2640. [CrossRef]

9. Saleemi, A.; Rielly, C.; Nagy, Z.K. Automated direct nucleation control for in situ dynamic fines removal in batch cooling crystallization. CrystEngComm 2012, 14, 2196-2203. [CrossRef]

10. Simone, E.; Saleemi, A.N.; Nagy, Z.K. In Situ Monitoring of Polymorphic Transformations Using a Composite Sensor Array of Raman, NIR, and ATR-UV/vis Spectroscopy, FBRM, and PVM for an Intelligent Decision Support System. Org. Process Res. Dev. 2015, 19, 167-177. [CrossRef]

11. Zhou, G.; Moment, A.; Cuff, J.; Schafer, W.; Orella, C.; Sirota, E.; Gong, X.; Welch, C. Process Development and Control with Recent New FBRM, PVM, and IR. Org. Process Res. Dev. 2014, 19, 227-235. [CrossRef]

12. Simone, E.; Saleemi, A.N.; Nagy, Z.K. Raman, UV, NIR, and Mid-IR Spectroscopy with Focused Beam Reflectance Measurement in Monitoring Polymorphic Transformations. Chem. Eng. Technol. 2014, 37, 1305-1313. [CrossRef]

13. Simon, L.L.; Nagy, Z.K.; Hungerbuhler, K. Comparison of external bulk video imaging with focused beam reflectance measurement and ultra-violet visible spectroscopy for metastable zone identification in food and pharmaceutical crystallization processes. Chem. Eng. Sci. 2009, 64, 3344-3351. [CrossRef]

14. Powell, K.A.; Croker, D.M.; Rielly, C.D.; Nagy, Z.K. Pat-based design of agrochemical co-crystallization processes: A case-study for the selective crystallization of 1:1 and 3:2 co-crystals of p-toluenesulfonamideitriphenylphosphine oxide. Chem. Eng. Sci. 2016, 152, 95-108. [CrossRef]

15. Peña, R.; Nagy, Z.K. Process Intensification through Continuous Spherical Crystallization Using a Two-Stage Mixed Suspension Mixed Product Removal (MSMPR) System. Cryst. Growth Des. 2015, 15, 4225-4236. [CrossRef]

16. Liu, W.J.; Wei, H.Y.; Zhao, J.T.; Black, S.; Sun, C. Investigation into the cooling crystallization and transformations of carbamazepine using in situ fbrm and pvm. Org. Process Res. Dev. 2013, 17, 1406-1412. [CrossRef]

17. Luo, Y.-H.; Tu, Y.-R.; Ge, J.-L.; Sun, B.-W. Monitoring the Crystallization Process of Methylprednisolone Hemisuccinate (MPHS) from Ethanol Solution by Combined ATR-FTIR- FBRM- PVM. Sep. Sci. Technol. 2013, 48, 1881-1890. [CrossRef]

18. Klapwijk, A.R.; Simone, E.; Nagy, Z.K.; Wilson, C.C. Tuning Crystal Morphology of Succinic Acid Using a Polymer Additive. Cryst. Growth Des. 2016, 16, 4349-4359. [CrossRef]

19. Koswara, A.N.Z.K. On-off feedback control of plug-flow crystallization: A case of quality-by-control in continuous manufacturing. IEEE Life Sci. Let. 2017, 3, 1-4. [CrossRef]

20. Simone, E.; Saleemi, A.; Nagy, Z. Application of quantitative Raman spectroscopy for the monitoring of polymorphic transformation in crystallization processes using a good calibration practice procedure. Chem. Eng. Res. Des. 2014, 92, 594-611. [CrossRef]

21. Samad, N.A.F.A.; Sin, G.; Gernaey, K.V.; Gani, R. A systematic framework for design of process monitoring and control (PAT) systems for crystallization processes. Comput. Chem. Eng. 2013, 54, 8-23. [CrossRef]

22. Damour, C.; Benne, M.; Grondin-Perez, B.; Chabriat, J.-P. Nonlinear predictive control based on artificial neural network model for industrial crystallization. J. Food Eng. 2010, 99, 225-231. [CrossRef]

23. Nagy, Z.K.; Braatz, R.D. Advances and New Directions in Crystallization Control. Annu. Rev. Chem. Biomol. Eng. 2012, 3, 55-75. [CrossRef]

24. Corriou, J.-P.; Rohani, S. A new look at optimal control of a batch crystallizer. AIChE J. 2008, 54, 3188-3206. [CrossRef] 
25. Lu, T.; Luo, F.; Mao, Z.; Wen, S. Parameters soft-sensing based on neural network in crystallizing process of cane sugar. In Proceedings of the 4th World Congress on Intelligent Control and Automation (Cat. No.02EX527), Shanghai, China, 10-14 June 2002. [CrossRef]

26. Iciek, J.; Jezierski, A. Neural model of relative mass flows of water and sugar in an installation for crystallizing and centrifuging A massecuite. Sugar Ind. 2010, 506-514. [CrossRef]

27. Pekalski, J.; Rzadkowski, W.; Panagiotopoulos, A.Z. Shear-induced ordering in systems with competing interactions: A ma-chine learning study. J. Chem. Phys. 2020, 152, 8. [CrossRef]

28. Gomez-Peralta, J.I.; Bokhimi, X. Discovering new perovskites with artificial intelligence. J. Solid State Chem. 2020, 285, 6. [CrossRef]

29. Braun, D.E.; Maas, S.G.; Zencirci, N.; Langes, C.; Urbanetz, N.A.; Griesser, U.J. Simultaneous quantitative analysis of ternary mixtures of d-mannitol polymorphs by FT-Raman spectroscopy and multivariate calibration models. Int. J. Pharm. 2010, 385, 29-36. [CrossRef]

30. Szilagyi, B.; Nagy, Z.K. Aspect Ratio Distribution and Chord Length Distribution Driven Modeling of Crystallization of TwoDimensional Crystals for Real-Time Model-Based Applications. Cryst. Growth Des. 2018, 18, 5311-5321. [CrossRef]

31. Szilagyi, B.; Nagy, Z.K. Real-time feasible model-based crystal size and shape control of crystallization processes. Comput. Aided Chem. Eng. 2019, 46, 1273-1278. [CrossRef]

32. Öner, M.; Montes, F.C.; Ståhlberg, T.; Stocks, S.M.; Bajtner, J.E.; Sin, G. Comprehensive evaluation of a data driven control strategy: Experimental application to a pharmaceutical crystallization process. Chem. Eng. Res. Des. 2020, 163, 248-261. [CrossRef]

33. Smiljanic, R.; Lazic, D.; Gligoric, M.; Jotanovic, M.; Zivkovic, Z.; Mihajlovic, I. Modelling the process of $\mathrm{Al}(\mathrm{OH})_{3} \mathrm{crystallization}$ from industrial sodium aluminate solutions using artificial neural networks. J. Serb. Chem. Soc. 2011, 76, 1163-1175. [CrossRef]

34. Fujiwara, M.; Nagy, Z.K.; Chew, J.W.; Braatz, R.D. First-principles and direct design approaches for the control of phar-maceutical crystallization. J. Process Contr. 2005, 15, 493-504. [CrossRef]

35. Saleemi, A.N.; Steele, G.; Pedge, N.I.; Freeman, A.; Nagy, Z.K. Enhancing crystalline properties of a cardiovascular active pharmaceutical ingredient using a process analytical technology based crystallization feedback control strategy. Int. J. Pharm. 2012, 430, 56-64. [CrossRef] [PubMed]

36. Tacsi, K.; Gyürkés, M.; Csontos, I.; Farkas, A.; Borbas, E.; Nagy, Z.K.; Marosi, G.; Pataki, H. Polymorphic Concentration Control for Crystallization Using Raman and Attenuated Total Reflectance Ultraviolet Visible Spectroscopy. Cryst. Growth Des. 2019, 20,73-86. [CrossRef]

37. Borsos, Á.; Szilágyi, B.; Agachi, P.Ş.; Nagy, Z.K. Real-Time Image Processing Based Online Feedback Control System for Cooling Batch Crystallization. Org. Process Res. Dev. 2017, 21, 511-519. [CrossRef]

38. Ostergaard, I.; Szilagyi, B.; De Diego, H.L.; Qu, H.; Nagy, Z.K. Polymorphic Control and Scale-Up Strategy for Antisolvent Crystallization Using a Sequential Supersaturation and Direct Nucleation Control Approach. Cryst. Growth Des. 2020, 20, 5538-5550. [CrossRef]

39. Griffin, D.J.; Kawajiri, Y.; Rousseau, R.W.; Grover, M.A. Using MC plots for control of paracetamol crystallization. Chem. Eng. Sci. 2017, 164, 344-360. [CrossRef]

40. Simone, E.; Saleemi, A.N.; Tonnon, N.; Nagy, Z.K. Active Polymorphic Feedback Control of Crystallization Processes Using a Combined Raman and ATR-UV/Vis Spectroscopy Approach. Cryst. Growth Des. 2014, 14, 1839-1850. [CrossRef]

41. Gron, H.; Borissova, A.; Roberts, K.J. In-process atr-ftir spectroscopy for closed-loop supersaturation control of a batch crys-tallizer producing monosodium glutamate crystals of defined size. Ind. Eng. Chem. Res. 2003, 42, 198-206. [CrossRef]

42. Nagy, Z.K.; Chew, J.W.; Fujiwara, M.; Braatz, R.D. Comparative performance of concentration and temperature controlled batch crystallizations. J. Process Control 2008, 18, 399-407. [CrossRef]

43. Zhou, G.X.; Fujiwara, M.; Woo, X.Y.; Rusli, E.; Tung, H.-H.; Starbuck, C.; Davidson, O.; Ge, Z.; Braatz, R.D. Direct Design of Pharmaceutical Antisolvent Crystallization through Concentration Control. Cryst. Growth Des. 2006, 6, 892-898. [CrossRef]

44. Liotta, V.; Sabesan, V. Monitoring and Feedback Control of Supersaturation Using ATR-FTIR to Produce an Active Pharmaceutical Ingredient of a Desired Crystal Size. Org. Process Res. Dev. 2004, 8, 488-494. [CrossRef]

45. Nonoyama, N.; Hanaki, K.; Yabuki, Y. Constant Supersaturation Control of Antisolvent-Addition Batch Crystallization. Org. Process Res. Dev. 2006, 10, 727-732. [CrossRef]

46. Hermanto, M.W.; Braatz, R.D.; Chiu, M.-S. Integrated batch-to-batch and nonlinear model predictive control for polymorphic transformation in pharmaceutical crystallization. AIChE J. 2010, 57, 1008-1019. [CrossRef]

47. Kalbasenka, A.N.; Spierings, L.C.P.; Huesman, A.E.M.; Kramer, H.J.M. Application of Seeding as a Process Actuator in a Model Predictive Control Framework for Fed-Batch Crystallization of Ammonium Sulphate. Part. Part. Syst. Charact. 2007, 24, 40-48. [CrossRef]

48. Hatakka, H.; Alatalo, H.; Louhi-Kultanen, M.; Lassila, I.; Haeggström, E.; Hæggström, E. Closed-Loop Control of Reactive Crystallization PART II: Polymorphism Control of L-Glutamic Acid by Sonocrystallization and Seeding. Chem. Eng. Technol. 2010, 33, 751-756. [CrossRef]

49. Alatalo, H.M.; Hatakka, H.; Louhi-Kultanen, M.; Kohonen, J.; Reinikainen, S.-P. Closed-Loop Control of Reactive Crystallization. Part I: Supersaturation-Controlled Crystallization of L-Glutamic Acid. Chem. Eng. Technol. 2010, 33, 743-750. [CrossRef]

50. Ostergaard, I.; Szilagyi, B.; Nagy, Z.K.; De Diego, H.L.; Qu, H. Polymorphic Control and Scale-up Strategy for Crystallization from a Ternary Antisolvent System by Supersaturation Control. Cryst. Growth Des. 2019, 20, 1337-1346. [CrossRef] 
51. Ma, C.Y.; Wang, X.Z. Model identification of crystal facet growth kinetics in morphological population balance modeling of l-glutamic acid crystallization and experimental validation. Chem. Eng. Sci. 2012, 70, 22-30. [CrossRef]

52. Saleemi, A.N.; Rielly, C.D.; Nagy, Z.K. Comparative Investigation of Supersaturation and Automated Direct Nucleation Control of Crystal Size Distributions using ATR-UV/vis Spectroscopy and FBRM. Cryst. Growth Des. 2012, 12, 1792-1807. [CrossRef]

53. Simone, E.; Nagy, Z.K. A link between the ATR-UV/Vis and Raman spectra of zwitterionic solutions and the polymorphic outcome in cooling crystallization. CrystEngComm 2015, 17, 6538-6547. [CrossRef]

54. Simone, E.; Zhang, W.; Nagy, Z.K. Application of Process Analytical Technology-Based Feedback Control Strategies To Improve Purity and Size Distribution in Biopharmaceutical Crystallization. Cryst. Growth Des. 2015, 15, 2908-2919. [CrossRef]

55. Kee, N.C.S.; Arendt, P.D.; Tan, R.B.H.; Braatz, R.D. Selective crystallization of the metastable anhydrate form in the en-antiotropic pseudo-dimorph system of 1-phenylalanine using concentration feedback control. Cryst. Growth Des. 2009, 9, 3052-3061. [CrossRef]

56. Kee, N.C.S.; Tan, R.B.H.; Braatz, R.D. Selective crystallization of the metastable alpha-form of l-glutamic acid using con-centration feedback control. Cryst. Growth Des. 2009, 9, 3044-3051. [CrossRef]

57. Zhou, G.; Moment, A.; Yaung, S.; Cote, A.; Hu, T.-E. Evolution and Application of an Automated Platform for the Development of Crystallization Processes. Org. Process Res. Dev. 2013, 17, 1320-1329. [CrossRef]

58. Khan, S.; Ma, C.Y.; Mahmud, T.; Penchev, R.Y.; Roberts, K.J.; Morris, J.; Oezkan, L.; White, G.; Grieve, B.; Hall, A.; et al. In-process monitoring and control of supersaturation in seeded batch cooling crystallisation of l-glutamic acid: From laboratory to industrial pilot plant. Org. Process Res. Dev. 2011, 15, 540-555. [CrossRef]

59. Kleinert, T.; Weickgenannt, M.; Judat, B.; Hagenmeyer, V. Cascaded two-degree-of-freedom control of seeded batch crystsallisations based on explicit system inversion. J. Process Control 2010, 20, 29-44. [CrossRef]

60. Chen, Z.; Lovett, D.; Morris, J. Process analytical technologies and real time process control a review of some spectroscopic issues and challenges. J. Process Control 2011, 21, 1467-1482. [CrossRef]

61. Duffy, D.; Barrett, M.; Glennon, B. Novel, Calibration-Free Strategies for Supersaturation Control in Antisolvent Crystallization Processes. Cryst. Growth Des. 2013, 13, 3321-3332. [CrossRef]

62. Blessy, M.; Patel, R.D.; Prajapati, P.N.; Agrawal, Y. Development of forced degradation and stability indicating studies of drugs-A review. J. Pharm. Anal. 2014, 4, 159-165. [CrossRef]

63. Lai, T.-T.C.; Cornevin, J.; Ferguson, S.; Li, N.; Trout, B.L.; Myerson, A.S. Control of Polymorphism in Continuous Crystallization via Mixed Suspension Mixed Product Removal Systems Cascade Design. Cryst. Growth Des. 2015, 15, 3374-3382. [CrossRef]

64. Abu Bakar, M.R.; Nagy, Z.K.; Saleemi, A.N.; Rielly, C.D. The Impact of Direct Nucleation Control on Crystal Size Distribution in Pharmaceutical Crystallization Processes. Cryst. Growth Des. 2009, 9, 1378-1384. [CrossRef]

65. Simon, L.L.; Pataki, H.; Marosi, G.; Meemken, F.; Hungerbühler, K.; Baiker, A.; Tummala, S.; Glennon, B.; Kuentz, M.; Steele, G.; et al. Assessment of Recent Process Analytical Technology (PAT) Trends: A Multiauthor Review. Org. Process Res. Dev. 2015, 19, 3-62. [CrossRef]

66. Woo, X.Y.; Nagy, Z.K.; Tan, R.B.H.; Braatz, R.D. Adaptive Concentration Control of Cooling and Antisolvent Crystallization with Laser Backscattering Measurement. Cryst. Growth Des. 2009, 9, 182-191. [CrossRef]

67. Doki, N.; Seki, H.; Takano, K.; Asatani, H.; Yokota, A.M.; Kubota, N. Process Control of Seeded Batch Cooling Crystallization of the Metastable $\alpha$-Form Glycine Using an In-Situ ATR-FTIR Spectrometer and an In-Situ FBRM Particle Counter. Cryst. Growth Des. 2004, 4, 949-953. [CrossRef]

68. Abu Bakar, M.R.; Nagy, Z.K.; Rielly, C.D. Investigation of the Effect of Temperature Cycling on Surface Features of Sulfathiazole Crystals during Seeded Batch Cooling Crystallization. Cryst. Growth Des. 2010, 10, 3892-3900. [CrossRef]

69. Kim, J.W.; Kim, J.K.; Kim, H.S.; Koo, K.K. Application of internal seeding and temperature cycling for reduction of liquid inclusion in the crystallization of rdx. Org. Process Res. Dev. 2011, 15, 602-609. [CrossRef]

70. Ostergaard, I.; Szilagyi, B.; De Diego, H.L.; Qu, H.; Nagy, Z.K. Polymorphic Control and Scale-Up Strategy for Antisolvent Crystallization Using Direct Nucleation Control. Cryst. Growth Des. 2020, 20, 2683-2697. [CrossRef]

71. Mangal, H.; Kleinebudde, P. Experimental determination of residence time distribution in continuous dry granulation. Int. J. Pharm. 2017, 524, 91-100. [CrossRef]

72. Meier, R.; Thommes, M.; Rasenack, N.; Moll, K.-P.; Krumme, M.; Kleinebudde, P. Granule size distributions after twin-screw granulation-Do not forget the feeding systems. Eur. J. Pharm. Biopharm. 2016, 106, 59-69. [CrossRef] [PubMed]

73. Madarász, L.; Köte, Á.; Gyürkés, M.; Farkas, A.; Hambalkó, B.; Pataki, H.; Fülöp, G.; Marosi, G.; Lengyel, L.; Casian, T.; et al. Videometric mass flow control: A new method for real-time measurement and feedback control of powder micro-feeding based on image analysis. Int. J. Pharm. 2020, 580, 119223. [CrossRef]

74. Sayin, R.; Martínez-Marcos, L.; Osorio, J.G.; Cruise, P.; Jones, I.; Halbert, G.W.; Lamprou, D.A.; Litster, J.D. Investigation of an 11 mm diameter twin screw granulator: Screw element performance and in-line monitoring via image analysis. Int. J. Pharm. 2015, 496, 24-32. [CrossRef]

75. D'Ausilio, A. Arduino: A low-cost multipurpose lab equipment. Behav. Res. Methods 2011, 44, 305-313. [CrossRef] [PubMed]

76. Bötschi, S.; Rajagopalan, A.K.; Morari, M.; Mazzotti, M. Feedback Control for the Size and Shape Evolution of Needle-like Crystals in Suspension. I. Concepts and Simulation Studies. Cryst. Growth Des. 2018, 18, 4470-4483. [CrossRef]

77. Rajagopalan, A.K.; Bötschi, S.; Morari, M.; Mazzotti, M. Feedback Control for the Size and Shape Evolution of Needle-like Crystals in Suspension. II. Cooling Crystallization Experiments. Cryst. Growth Des. 2018, 18, 6185-6196. [CrossRef] 
78. Bötschi, S.; Rajagopalan, A.K.; Morari, M.; Mazzotti, M. Feedback Control for the Size and Shape Evolution of Needle-like Crystals in Suspension. IV. Modeling and Control of Dissolution. Cryst. Growth Des. 2019, 19, 4029-4043. [CrossRef]

79. Rajagopalan, A.K.; Bötschi, S.; Morari, M.; Mazzotti, M. Feedback Control for the Size and Shape Evolution of Needle-like Crystals in Suspension. III. Wet Milling. Cryst. Growth Des. 2019, 19, 2845-2861. [CrossRef]

80. Simon, L.L.; Simone, E.; Oucherif, K.A. Crystallization process monitoring and control using process analytical technology. Comput. Aided Chem. Eng. 2018, 215-242. [CrossRef]

81. Hirsch, E.; Pataki, H.; Farkas, A.; Bata, H.; Vass, P.; Fehér, C.; Barta, Z.; Párta, L.; Csontos, I.; Ballagi, A.; et al. Raman-Based Feedback Control of the Enzymatic Hydrolysis of Lactose. Org. Process Res. Dev. 2016, 20, 1721-1727. [CrossRef]

82. Pataki, H.; Csontos, I.; Nagy, Z.K.; Vajna, B.; Molnar, M.; Katona, L.; Marosi, G. Implementation of Raman Signal Feedback to Perform Controlled Crystallization of Carvedilol. Org. Process Res. Dev. 2012, 17, 493-499. [CrossRef]

83. Simone, E.; Szilagyi, B.; Nagy, Z. Systematic model identification and optimization-based active polymorphic control of crystallization processes. Chem. Eng. Sci. 2017, 174, 374-386. [CrossRef]

84. Hulburt, H.M.; Katz, S. Some problems in particle technology: A statistical mechanical formulation. Chem. Eng. Sci. 1964, 19, 555-574. [CrossRef]

85. Randolph, A.D. A population balance for countable entities. Can. J. Chem. Eng. 1964, 42, 280-281. [CrossRef]

86. Griffin, D.J.; Grover, M.A.; Kawajiri, Y.; Rousseau, R.W. Mass-count plots for crystal size control. Chem. Eng. Sci. 2015, 137, 338-351. [CrossRef]

87. Griffin, D.J.; Grover, M.A.; Kawajiri, Y.; Rousseau, R.W. Data-Driven Modeling and Dynamic Programming Applied to Batch Cooling Crystallization. Ind. Eng. Chem. Res. 2016, 55, 1361-1372. [CrossRef]

88. Grover, M.A.; Griffin, D.J.; Tang, X.; Kim, Y.; Rousseau, R.W. Optimal feedback control of batch self-assembly processes using dynamic programming. J. Process Control 2020, 88, 32-42. [CrossRef]

89. Grover, M.A.; Griffin, D.J.; Tang, X. Control of Self-Assembly with Dynamic Programming. IFAC-PapersOnLine 2019, 52,1-9. [CrossRef]

90. Kovaleva, E.L.; Bagirova, V.L.; Shanazarov, K.S. Developing methodological approaches to standardization of pharmaceutical substances. Pharm. Chem. J. 2010, 44, 33-39. [CrossRef]

91. Olefir, Y.V.; Sakanyan, E.I.; Shishova, L.I.; Senchenko, S.P. Pharmacopoeial Quality Requirements for Medicinal Products. Pharm. Chem. J. 2019, 52, 936-941. [CrossRef]

92. Wu, H.; Dong, Z.; Li, H.; Khan, M. An integrated process analytical technology (pat) approach for pharmaceutical crystallization process understanding to ensure product quality and safety: Fda scientist's perspective. Org. Process Res. Dev. 2015, 19, 89-101. [CrossRef]

93. Cruz-Cabeza, A.J.; Reutzel-Edens, S.M.; Bernstein, J. Facts and fictions about polymorphism. Chem. Soc. Rev. 2015, 44, 8619-8635. [CrossRef] [PubMed]

94. Singhal, D.; Curatolo, W. Drug polymorphism and dosage form design: A practical perspective. Adv. Drug. Deliver. Rev. 2004, 56, 335-347. [CrossRef]

95. Coté, A.; Zhou, G.; Stanik, M. A Novel Crystallization Methodology To Ensure Isolation of the Most Stable Crystal Form. Org. Process Res. Dev. 2009, 13, 1276-1283. [CrossRef]

96. Zhang, T.; Szilagyi, B.; Gong, J.; Nagy, Z.K. Thermodynamic polymorph selection in enantiotropic systems using supersaturationcontrolled batch and semibatch cooling crystallization. Cryst. Growth Des. 2019, 19, 6715-6726. [CrossRef]

97. Ma, L.-J.; Guo, L.-J. Study of the phase transformation of TiO2 with in-situ XRD in different gas. Guang pu xue yu Guang pu fen xi = Guang pu 2011, 31, 1133-1137. [PubMed]

98. Heinrich, J.; Elter, T.; Ulrich, J. Data Preprocessing of In Situ Laser-Backscattering Measurements. Chem. Eng. Technol. 2011, 34, 977-984. [CrossRef]

99. Prediger, A.; Bluma, A.; Hoepfner, T.; Lindner, P.; Beutel, S.; Mueller, J.J.; Hilterhaus, L.; Liese, A.; Scheper, T. In Situ mi-croscopy for online monitoring of enzyme supports and two-phase systems. Chem. Ing. Tech. 2011, 83, 884-887. [CrossRef]

100. Howard, K.S.; Nagy, Z.K.; Saha, B.; Robertson, A.L.; Steele, G.; Martin, D. A Process Analytical Technology Based Investigation of the Polymorphic Transformations during the Antisolvent Crystallization of Sodium Benzoate from IPA/Water Mixture. Cryst. Growth Des. 2009, 9, 3964-3975. [CrossRef]

101. Veintemillas-Verdaguer, S.J.P.I.C.G. Chemical aspects of the effect of impurities in crystal growth. Prog. Cryst. Growth Charact. Mater. 1996, 32, 75-109. [CrossRef]

102. Darmali, C.; Mansouri, S.; Yazdanpanah, N.; Woo, M.W. Mechanisms and Control of Impurities in Continuous Crystallization: A Review. Ind. Eng. Chem. Res. 2018, 58, 1463-1479. [CrossRef]

103. Nagy, Z.; Aamir, E. Systematic design of supersaturation controlled crystallization processes for shaping the crystal size distribution using an analytical estimator. Chem. Eng. Sci. 2012, 84, 656-670. [CrossRef]

104. Krishnaiah, C.; Reddy, A.R.; Kumar, R.; Mukkanti, K. Stability-indicating UPLC method for determination of Valsartan and their degradation products in active pharmaceutical ingredient and pharmaceutical dosage forms. J. Pharm. Biomed. Anal. 2010, 53, 483-489. [CrossRef]

105. Ali, N.W.; Abbas, S.S.; Zaazaa, H.E.-S.; Abdelrahman, M.M.; Abdelkawy, M. Validated stability indicating methods for determination of nitazoxanide in presence of its degradation products. J. Pharm. Anal. 2012, 2, 105-116. [CrossRef] 
106. Borsos, A.; Majumder, A.; Nagy, Z.K. Multi-Impurity Adsorption Model for Modeling Crystal Purity and Shape Evolution during Crystallization Processes in Impure Media. Cryst. Growth Des. 2015, 16, 555-568. [CrossRef]

107. Pal, K.; Yang, Y.; Nagy, Z.K. Model-based optimization of cooling crystallization of active pharmaceutical ingredients undergoing thermal degradation. Cryst. Growth Des. 2019, 19, 3417-3429. [CrossRef]

108. Amrani, F.; Secrétan, P.-H.; Sadou-Yayé, H.; Aymes-Chodur, C.; Bernard, M.; Solgadi, A.; Yagoubi, N.; Do, B. Identification of dabigatran etexilate major degradation pathways by liquid chromatography coupled to multi stage high-resolution mass spectrometry. RSC Adv. 2015, 5, 45068-45081. [CrossRef]

109. Zhang, T.; Szilágyi, B.; Gong, J.; Nagy, Z.K. Novel semibatch supersaturation control approach for the cooling crystallization of heat-sensitive materials. AIChE J. 2020, 66. [CrossRef]

110. Lovette, M.A.; Browning, A.R.; Griffin, D.W.; Sizemore, J.P.; Snyder, R.C.; Doherty, M.F. Crystal Shape Engineering. Ind. Eng. Chem. Res. 2008, 47, 9812-9833. [CrossRef]

111. Variankaval, N.; Cote, A.S.; Doherty, M.F. From form to function: Crystallization of active pharmaceutical ingredients. AIChE J. 2008, 54, 1682-1688. [CrossRef]

112. Yang, Y.; Pal, K.; Koswara, A.; Sun, Q.; Zhang, Y.; Quon, J.; McKeown, R.; Goss, C.; Nagy, Z.K. Application of feedback control and in situ milling to improve particle size and shape in the crystallization of a slow growing needle-like active pharmaceutical ingredient. Int. J. Pharm. 2017, 533, 49-61. [CrossRef] [PubMed]

113. Majumder, A.; Nagy, Z.K. Prediction and control of crystal shape distribution in the presence of crystal growth modifiers. Chem. Eng. Sci. 2013, 101, 593-602. [CrossRef]

114. Eisenschmidt, H.; Voigt, A.; Sundmacher, K. Face-Specific Growth and Dissolution Kinetics of Potassium Dihydrogen Phosphate Crystals from Batch Crystallization Experiments. Cryst. Growth Des. 2014, 15, 219-227. [CrossRef]

115. Eisenschmidt, H.; Bajcinca, N.; Sundmacher, K. Optimal Control of Crystal Shapes in Batch Crystallization Experiments by Growth-Dissolution Cycles. Cryst. Growth Des. 2016, 16, 3297-3306. [CrossRef]

116. Nagy, Z.K. Model based robust control approach for batch crystallization product design. Comput. Chem. Eng. 2009, 33, 1685-1691. [CrossRef]

117. Larsen, P.A.; Patience, D.B.; Rawlings, J.B. Industrial crystallization process control. IEEE Control. Syst. 2006, 26, 70-80. [CrossRef] 